\title{
Palmitoylation Controls NMDA Receptor Function and Steroid Sensitivity
}

\author{
Pavla Hubalkova, ${ }^{1,3}$ Marek Ladislav, ${ }^{1}$ Dojtech Vyklicky, ${ }^{1}$ Tereza Smejkalova, ${ }^{1}$ Barbora Hrcka Krausova, ${ }^{1}$ \\ Bohdan Kysilov, ${ }^{1}$ Jan Krusek, ${ }^{1}$ Zaneta Naimová, ${ }^{1}$ Miloslav Korinek, ${ }^{1}$ Hana Chodounska, ${ }^{2}$ Eva Kudova, ${ }^{2}$ \\ ${ }^{(1)}$ Jiri Cerny, ${ }^{1 \star}$ and Ladislav Vyklicky Jr ${ }^{1 \star}$ \\ ${ }^{1}$ Institute of Physiology CAS, Prague 4, 142 20, Czech Republic, ${ }^{2}$ Institute of Organic Chemistry and Biochemistry CAS, Prague 2, 166 10, Czech \\ Republic, and ${ }^{3}$ Third Faculty of Medicine, Charles University in Prague, Prague 10, 100 00, Czech Republic
}

NMDARs are ligand-gated ion channels that cause an influx of $\mathrm{Na}^{+}$and $\mathrm{Ca}^{2+}$ into postsynaptic neurons. The resulting intracellular $\mathrm{Ca}^{2+}$ transient triggers synaptic plasticity. When prolonged, it may induce excitotoxicity, but it may also activate negative feedback to control the activity of NMDARs. Here, we report that a transient rise in intracellular $\mathrm{Ca}^{2+}\left(\mathrm{Ca}^{2+}\right.$ challenge) increases the sensitivity of NMDARs but not AMPARs/kainate receptors to the endogenous inhibitory neurosteroid 20-oxo$5 \beta$-pregnan-3 $\alpha$-yl 3-sulfate and to its synthetic analogs, such as 20-oxo-5 $\beta$-pregnan-3 $\alpha$-yl 3-hemipimelate (PAhPim). In cultured hippocampal neurons, $30 \mu \mathrm{M}$ PAhPim had virtually no effect on NMDAR responses; however, following the $\mathrm{Ca}^{2+}$ challenge, it inhibited the responses by $62 \%$; similarly, the $\mathrm{Ca}^{2+}$ challenge induced a 3.7 -fold decrease in the steroid $\mathrm{IC}_{50}$ on recombinant GluN1/GluN2B receptors. The increase in the NMDAR sensitivity to PAhPim was dependent on three cysteines (C849, C854, and C871) located in the carboxy-terminal domain of the GluN2B subunit, previously identified to be palmitoylated (Hayashi et al., 2009). Our experiments suggested that the $\mathrm{Ca}^{2+}$ challenge induced receptor depalmitoylation, and single-channel analysis revealed that this was accompanied by a 55\% reduction in the probability of channel opening. Results of in silico modeling indicate that receptor palmitoylation promotes anchoring of the GluN2B subunit carboxy-terminal domain to the plasma membrane and facilitates channel opening. Depalmitoylation-induced changes in the NMDAR pharmacology explain the neuroprotective effect of PAhPim on NMDA-induced excitotoxicity. We propose that palmitoylation-dependent changes in the NMDAR sensitivity to steroids serve as an acute endogenous mechanism that controls NMDAR activity.

Key words: carboxy-terminal domain; molecular dynamics simulation; neurosteroid; NMDAR; palmitoylation; singlechannel recording

Significance Statement

There is considerable interest in negative allosteric modulators of NMDARs that could compensate for receptor overactivation by glutamate or de novo gain-of-function mutations in neurodevelopmental disorders. By a combination of electrophysiological, pharmacological, and computational techniques we describe a novel feedback mechanism regulating NMDAR activity. We find that a transient rise in intracellular $\mathrm{Ca}^{2+}$ increases NMDAR sensitivity to inhibitory neurosteroids in a process dependent on GluN2B subunit depalmitoylation. These results improve our understanding of the molecular mechanisms of steroid action at the NMDAR and indeed of the basic properties of this important glutamate-gated ion channel and may aid in the development of therapeutics for treating neurologic and psychiatric diseases related to overactivation of NMDARs without affecting normal physiological functions.

Received Oct. 15, 2020; revised Dec. 8, 2020; accepted Jan. 6, 2021.

Author contributions: L.V. and V.V. designed research; L.V., P.H., M.L., V.V., T.S., B.H.K., B.K., J.K., Z.N., and J.C. analyzed data; L.V. wrote the first draft of the paper; L.V. and J.C. wrote the paper; P.H., M.L., V.V., T.S., B.H.K., B.K., J.K., Z.N., M.K., and J.C. performed research; T.S. and M.K. edited the paper; H.C. and E.K. contributed unpublished reagents/analytic tools.

This work was supported by Czech Science Foundation 20-17945S and 16-03913Y; Technology Agency of the Czech Republic TN01000013; Grant Agency of Charles University 928216; ERDF/ESF project PharmaBrain CZ.02.1.01/0.0/0.0/16_025/0007444; Research Project of the AS CR RV0 67985823 and RVO 61388963; and Biotechnology and Biomedicine Center of Academy of Sciences and Charles
University in Vestec (project supported from European Regional Development Fund). We thank Magda Kuntosova for excellent technical assistance; and Dr. Martin Horak for the gift of DNA constructs (GluN1_R839X, GluN2B_R847X).

The authors declare no competing financial interests.

Correspondence should be addressed to Ladislav Vyklicky at ladislav.vyklicky@fgu.cas.cz or Jiri Cerny at jiri.cerny@ibt.cas.cz.

https://doi.org/10.1523/JNEUROSCI.2654-20.2021

Copyright $\odot 2021$ the authors 


\section{Introduction}

NMDARs are members of the glutamate-gated ion channel superfamily. They mediate a component of excitatory synaptic transmission in virtually all CNS circuits to regulate physiological functions and synaptic plasticity (Traynelis et al., 2010). NMDARs are heterotetramers, composed of four subunits: two GluN1 and two GluN2 and/or GluN3 subunits (Moriyoshi et al., 1991; Kutsuwada et al., 1992; Meguro et al., 1992; Monyer et al., 1992; Sucher et al., 1995; Hansen et al., 2018) . Each subunit consists of an amino-terminal domain (ATD) and a ligand-binding domain (LBD), both oriented extracellularly, a transmembrane domain (TMD) that forms the ion channel, and an intracellular carboxy-terminal domain (CTD) that has regulatory functions (Karakas and Furukawa, 2014; Hardingham, 2019).

Glutamate released phasically from presynaptic terminals or ambient glutamate present in the extracellular space leads to NMDAR activation and $\mathrm{Ca}^{2+}$ influx through these cation-permeant ion channels (Mayer et al., 1987). Under physiological conditions, NMDAR-mediated rise in postsynaptic $\mathrm{Ca}^{2+}$ activates numerous signaling pathways essential for synaptic development and plasticity (Constantine-Paton et al., 1990; Lynch, 2004; Malenka and Bear, 2004; Bouvier et al., 2018). Under pathologic conditions, prolonged increase in $\mathrm{Ca}^{2+}$ can lead to excitotoxic cell death, associated, for example, with stroke, traumatic brain injury, or neurodegenerative diseases (Choi, 1987; Hardingham and Bading, 2010). Since NMDARs are fundamental for maintaining normal brain function, with neurologic and psychiatric consequences when dysregulated, the activity of these receptors is controlled by a wide array of endogenous agents, including small monovalent and divalent ions $\left(\mathrm{H}^{+}\right.$, $\left.\mathrm{Mg}^{2+}, \mathrm{Zn}^{2+}, \mathrm{Cu}^{2+}\right)$, and allosteric modulators, such as neurosteroids and fatty acids (Hansen et al., 2018).

On a longer-term basis, the activity of NMDARs is dynamically regulated by post-translational modifications, such as phosphorylation, ubiquitination, and palmitoylation (Traynelis et al., 2010; Lussier et al., 2015), with some pathways directly activated by intracellular $\mathrm{Ca}^{2+} \cdot \mathrm{Ca}^{2+}$-triggered post-translational modifications can enhance NMDAR function in the context of synaptic plasticity. NMDAR phosphorylation by kinases, such as PKC or CaMKII, can influence receptor trafficking and channel gating, resulting in increased synaptic strength (Vieira et al., 2020). On the other hand, $\mathrm{Ca}^{2+}$ influx can also activate autoinhibitory feedback mechanisms. These include $\mathrm{Ca}^{2+}$-calmodulin binding to the CTD of the GluN1 subunit to reversibly reduce the open probability $\left(\mathrm{P}_{\mathrm{o}}\right)$ of the NMDAR ion channel (Ehlers et al., 1996; Krupp et al., 1999; Iacobucci and Popescu, 2020; Warnet et al., 2020), or calcineurin-dependent NMDAR desensitization (Tong et al., 1995; Lan et al., 2001; Maki et al., 2012). In turn, the $\mathrm{Ca}^{2+}$ permeability of neuronal NMDARs is regulated by the cAMPPKA signaling cascade (Skeberdis et al., 2006; Murphy et al., 2014). In many cases, the molecular mechanisms that trigger post-translational modification of NMDARs, as well as the consequences of the modification on receptor function, pharmacology, stability, trafficking, and synaptic expression are still poorly understood.

This study demonstrates a novel form of $\mathrm{Ca}^{2+}$-dependent inhibitory feedback where the sensitivity of native NMDARs and recombinant GluN1/GluN2B receptors to the endogenous inhibitory neurosteroid 20-oxo-5 $\beta$-pregnan-3 $\alpha$-yl 3 -sulfate (PAS) and its synthetic analogs is increased following receptor stimulation in the presence of $\mathrm{Ca}^{2+}$. The upregulation of the receptor sensitivity to steroids is triggered by the intracellular $\mathrm{Ca}^{2+}$ transient and is dependent on the CTD of the GluN2B subunit. The critical region is located immediately adjacent to the M4 domain where cysteine residues C849, C854, and C871 can be palmitoylated to modulate NMDAR activity.

\section{Materials and Methods}

Transfection and maintenance of cells

Electrophysiological experiments were performed as described previously, 24-48 h after transfection of cultured human embryonic kidney 293 (HEK) cells with cDNA containing GluN1-1a/GluN2B/GFP genes (GenBank accession number U08261 and M91562) (Borovska et al., 2012) and on cultured hippocampal neurons at DIV 8-13 (Vyklicky et al., 2016).

Site-directed mutagenesis was performed using the QuikChange II XL Site-Directed Mutagenesis Kit (Agilent Technologies) in accordance with the instructions of the manufacturer, using manually designed primers purchased from Sigma Millipore. PCR was performed and the DpnI-treated product was transformed into ultracompetent XL10-Gold Escherichia coli cells, positive clones were selected, and the presence of all mutations was verified by DNA sequencing (Eurofins Genomics). Amino acids are numbered according to the full-length protein, including the signal peptide, with the initiating methionine as number 1 .

For neuronal cultures, glass coverslips were coated with $0.1 \mathrm{mg} / \mathrm{ml}$ poly-D-lysine and $0.2 \mathrm{mg} / \mathrm{ml}$ collagen (Serva). Primary cortical astrocyte cultures were prepared from postnatal day 1 male Wistar rat pups and grown for 1-2 weeks in DMEM with GlutaMax (Invitrogen), 10\% FBS (Invitrogen), and penicillin/streptomycin before being plated on coated coverslips at $\sim 6000 \mathrm{cells} / \mathrm{cm}^{2}$. Hippocampal neurons were isolated from postnatal day 1 male Wistar rat pups and plated on top of the astrocyte layer at $\sim 50,000$ cells $/ \mathrm{cm}^{2}$ in Neurobasal A medium with B27 Supplement (Invitrogen), GlutaMax, and penicillin/streptomycin.

\section{Electrophysiological recording}

All drugs, unless otherwise stated, were purchased from Sigma Millipore. Experiments were performed at room temperature $\left(21^{\circ} \mathrm{C}-24^{\circ} \mathrm{C}\right)$.

Whole-cell recording. Responses were recorded using a patch-clamp amplifier (Axopatch 200B; Molecular Devices) after series resistance $(<10 \mathrm{M} \Omega)$ and capacitance compensation of $80 \%-90 \%$. For the application of test and control solutions, a microprocessor-controlled multibarrel fast perfusion system was used, with a time constant of solution exchange around the cells of $\sim 10 \mathrm{~ms}$. Agonist-induced responses were low-pass filtered at $2 \mathrm{kHz}$, digitally sampled at $5 \mathrm{kHz}$, and analyzed with pClamp software version 10.4 (Molecular Devices). Patch pipettes (3-5 $\mathrm{M} \Omega$ ) pulled from borosilicate glass were filled with a $\mathrm{Cs}^{+}$-based intracellular solution (ICS) containing the following (in $\mathrm{mM}$ ): 125 gluconic acid $\delta$-lactone, $15 \mathrm{CsCl}, 5 \mathrm{EGTA}, 10 \mathrm{HEPES}, 3 \mathrm{MgCl}_{2}, 0.5 \mathrm{CaCl}_{2}$, and $2 \mathrm{ATP}-$ $\mathrm{Mg}$ salt (pH adjusted to 7.2 with $\mathrm{CsOH}$ ). Extracellular solution (ECS) contained the following (in mM): $160 \mathrm{NaCl}, 2.5 \mathrm{KCl}, 10 \mathrm{HEPES}, 10$ glucose, $0.3 \mathrm{CaCl}_{2}$, and 0.1 EDTA (pH adjusted to 7.3 with $\mathrm{NaOH}$ ). NMDAR responses were induced by $1 \mu \mathrm{M}$ or $1 \mathrm{~mm}$ glutamate (in recombinant receptors) and $10 \mu \mathrm{M}$ or $100 \mu \mathrm{M}$ NMDA (in native receptors) applied together with $10 \mu \mathrm{M}$ glycine. The ECS used for native receptors had the same composition as the ECS used for recombinant receptors. For native NMDAR recordings, the ECS additionally contained $10 \mu \mathrm{M}$ CNQX, $10 \mu \mathrm{M}$ bicuculline, and $0.5 \mu \mathrm{M}$ TTX (all from Tocris Bioscience). AMPAR currents were induced with $5 \mu \mathrm{M}$ AMPA, and the ECS additionally contained $50 \mu \mathrm{M}$ D-AP5, $10 \mu \mathrm{m}$ bicuculline, 0.5 $\mu \mathrm{M}$ TTX, and $10 \mu \mathrm{M}$ cyclothiazide (all from Tocris Bioscience). For the $\mathrm{Ca}^{2+}$ challenge, the ECS contained $2 \mathrm{mM} \mathrm{CaCl}_{2}$. Steroids were dissolved in DMSO and added to the ECS at the indicated concentrations, with the final DMSO concentration of $1 \%$. An equivalent amount of DMSO was present in control solutions. Tunicamycin was dissolved in DMSO to create a stock solution of $10 \mathrm{mg} / \mathrm{ml}$ and stored at $4^{\circ} \mathrm{C}$. Transfected HEK cells were incubated with tunicamycin (final concentration $1 \mu \mathrm{g} / \mathrm{ml}$ ) in serum-free media for $1-2 \mathrm{~h}$ before electrophysiological recordings.

Single-channel recording. Stationary one-channel activity was recorded at room temperature using the cell-attached patch-clamp technique. Recordings were analog-filtered at $10 \mathrm{kHz}$ with a 4-pole Bessel 
filter and sampled at $25 \mathrm{kHz}$. Thick-wall borosilicate patch pipettes were pulled and fire-polished, achieving resistances of 12-25 $\mathrm{m} \Omega$ and filled with $\mathrm{Ca}^{2+}$-free ECS containing the following (in $\mathrm{mM}$ ): $160 \mathrm{NaCl}, 2.5$ $\mathrm{KCl}, 1$ EDTA, $10 \mathrm{HEPES}, 0.1$ glycine, and 1 glutamate (adjusted to $\mathrm{pH}$ 7.3 with $\mathrm{NaOH}$ ). Recordings were performed in the absence of divalent ions (1 mM EDTA) to achieve unitary current. Inward openings were detected by applying a pipette potential of $100 \mathrm{mV}$ (estimated holding potential of $-130 \mathrm{mV}$ ).

\section{Data analysis}

Analysis of the steroid effect. The relative degree of the steroid inhibition of Control $\left(E_{\text {Control }}\right)$ and Test $\left(E_{\text {Test }}\right)$ responses was calculated as follows:

$$
E=\left(1-\left(I_{S} / I_{A}\right)\right) \times 100
$$

where $I_{A}$ is the amplitude of the agonist-induced response and $I_{S}$ is the amplitude of the response recorded in the presence of the agonist and the steroid.

Difference in the steroid-induced inhibition of Control and Test responses $(\Delta E)$ was calculated as follows:

$$
\Delta E=E_{\text {Test }}-E_{\text {Control }}
$$

where $E_{\text {Test }}$ and $E_{\text {Control }}$ are the relative degrees of the steroid inhibition of Test and Control responses, respectively.

The relative agonist-induced responses $\left(I ; I=I_{S} / I_{A}\right)$ recorded in the presence of the steroid and determined in individual cells were fit to the following logistic equation:

$$
I=1 /\left(1+\left([\text { steroid }] / \mathrm{IC}_{50}\right)^{h}\right)
$$

where [steroid] is the steroid concentration, $I C_{50}$ is the steroid concentration that produces a $50 \%$ inhibition of agonist-evoked current, and $h$ is the apparent Hill coefficient.

Analysis of inactivation. Inactivation of NMDAR responses $(A)$ was calculated as follows:

$$
A=\left(1-\left(I_{\text {ATest }} / I_{\text {AControl }}\right)\right) \times 100
$$

where $I_{\text {ATest }}$ is the amplitude of the agonist-induced Test response (after the $\mathrm{Ca}^{2+}$ challenge) and $I_{A \text { Control }}$ is the amplitude of the agonist-induced Control response (before the $\mathrm{Ca}^{2+}$ challenge).

Analysis of single-channel activity. Data analysis was performed on recorded patches that contained enough events in control $(>4000$ events) and were entirely free of overlapping openings ( $99 \%$ confidence of having just one channel in the patch) (Colquhoun and Hawkes, 1990) using QuB software (State University of New York). The data were idealized with a segmental $k$-means algorithm (F. Qin, 2004) using a digital low-pass filter at $12 \mathrm{kHz}$ and applying $0.12 \mathrm{~ms}$ of dead time. The analysis of idealized data was performed with the maximum interval likelihood algorithm (F. Qin et al., 1997; Amico-Ruvio and Popescu, 2010).

Kinetic analysis was performed on patches with a minimum of 10min-long recordings; the first $10 \mathrm{~min}$ was analyzed and compared between WT and mutated GluN1/GluN2B receptors. Models were created based on log-likelihood improvement of 10 units per added state and contained four open states and five closed states (5C4O) where $\mathrm{C} 4$ and $\mathrm{C} 5$ represent long-lived nonconductive states of desensitization and inactivation, respectively. C1, C2, and C3 represent closed states within bursts. For each patch, two open states can be identified (fast and slow), and the slow open state can be further divided into three modes (low, medium, and high) (Amico-Ruvio and Popescu, 2010).

\section{$\mathrm{Ca}^{2+}$ imaging}

Standard whole-cell patch-clamp method was used. Borosilicate glass pipettes (3-5 $\mathrm{M} \Omega$ ) were filled with the standard ICS supplemented with $100 \mu \mathrm{M}$ fura-2 (Invitrogen). Microspectrofluorometric measurements of $\mathrm{Ca}^{2+}$ currents were performed under the control of Cella $\mathrm{R}$ software
(Olympus) using a CellaR imaging system built on IX81 microscope (Olympus), using Polychrome V illuminator (Till Photonics). Fluorescence emission was detected by an Orca-ER cooled camera (Hamamatsu Photonics). Fluorescence images were obtained by exposing cells to $340 \mathrm{~nm}$ and $380 \mathrm{~nm}$ excitation light alternating under computer control. The emitted light signal $(>510 \mathrm{~nm})$ was stored as pairs of images and the ratio of paired images (F340/F380) was calculated.

\section{Excitotoxicity assay}

Primary hippocampal cultures at DIV 12 were treated with various concentrations of $\operatorname{NMDA}(3,10$, or $30 \mu \mathrm{M})$ and with 20 -oxo- $5 \beta$-pregnan$3 \alpha$-yl 3-hemipimelate (PAhPim) $(30 \mu \mathrm{M})$ or the corresponding volume of DMSO vehicle $(0.3 \%)$ for $2 \mathrm{~h}$ at $37^{\circ} \mathrm{C}$ in complete MEM (MEM salt solution containing the following [in $\mathrm{mM}$ ]: $120 \mathrm{NaCl}$, $5 \mathrm{KCl}, 25 \mathrm{NaHCO}_{3}, 1 \mathrm{NaH}_{2} \mathrm{PO}_{4} \cdot 2 \mathrm{H}_{2} \mathrm{O}, 2 \mathrm{CaCl}_{2}, 1 \mathrm{MgCl}_{2}$, supplemented with MEM amino acids and MEM vitamins [Invitrogen], $10 \mathrm{~mm}$ glucose, and $30 \mu \mathrm{m}$ glycine). After the treatment, cultures were washed with conditioned Neurobasal medium collected before the treatment, and were maintained at $37^{\circ} \mathrm{C}$ overnight. The next day, $5 \mu \mathrm{M}$ Hoechst 33342 dye $(\mathrm{H})$ and $6 \mu \mathrm{M}$ propidium iodide (PI) were added to the media for $30 \mathrm{~min}$ at $37^{\circ} \mathrm{C}$. Cultures were then washed with standard ECS. Fluorescence of $\mathrm{H}$ (excitation at $380 \mathrm{~nm}$ ) and PI (excitation at $540 \mathrm{~nm}$ ) was measured using the Cella $\mathrm{R}$ imaging system (Olympus) in ECS at $24^{\circ} \mathrm{C}$. The quantification was performed using ImageJ 1.52 (National Institutes of Health). In each FOV, the total number of neuronal nuclei was estimated from the Hoechst staining $\left(\mathrm{H}_{\mathrm{N}}\right)$, based on the characteristic higher-intensity staining of neuronal versus astrocyte nuclei. The number of necrotic nuclei was determined from the PI staining. The \% of dead neurons $(D)$ was calculated as follows:

$$
D=\left(P I / H_{N}\right) \times 100
$$

\section{Steroid synthesis}

The steroids were prepared by multistep synthetic procedures as described previously: PAS (Stastna et al., 2009), PAhPim (Vyklicky et al., 2016), and (3S)-3-(amino)-4-((5 $\beta$-androstan-3 $\alpha$-yl)-amino)-4-oxobutanoic acid (ANDAsp) (Adla et al., 2017). The structures of all synthesized steroids were confirmed by ${ }^{1} \mathrm{H}$ and ${ }^{13} \mathrm{C}$ NMR, MS, and HR-MS spectra.

\section{Statistical analysis}

All data are expressed as mean \pm SEM. Group differences were analyzed using Student's $t$ test or one-way ANOVA followed by multiple comparison procedures when indicated, using the statistical software package SigmaStat 3.5 (Systat Software).

\section{Molecular modeling}

Homology modeling. The initial model of the GluN2B segment M4E878X containing residues 811-877 of the rat GluN2B subunit (numbering according to the uniport id Q00960) (UniProt, 2019) was built in MODELLER 9.23 (Sali and Blundell, 1993; Webb and Sali, 2014) using the automodel function. Our previously prepared GluN1/GluN2B homology model (Ladislav et al., 2018), based on the available structures 4pe5, 4tll, and 4tlm (Karakas and Furukawa, 2014; C. H. Lee et al., 2014), was extended at the C-termini and the M4-E878X segment extracted from the produced model.

Molecular dynamics (MD) simulations. The simulations of the M4E878X segment of the GluN2B model were prepared using CHARMMGUI (Jo et al., 2008; J. Lee et al., 2016) by introducing the palmitoyl modifications of cysteine residues C849, C854, and C871 where necessary, and inserting the model into a membrane containing DOPC and cholesterol (1:1). The simulation box $(100 \AA \times 100 \AA \times 97 \AA)$ was filled with TIP3P water and a charge-neutral system with a final salt concentration of $150 \mathrm{~mm}$ was created adding $\mathrm{Na}^{+}$and $\mathrm{Cl}^{-}$ions. $\mathrm{MD}$ simulations of 200 ns were performed using Gromacs 2018.8 (Abraham et al., 2015) and CHARMM36 forcefield (Klauda et al., 2010) with the Nosé-Hoover thermostat and the Parrinello-Rahman barostat collecting the geometry 
every $10 \mathrm{ps}$. Visualization of structures, graphical representation, and the analysis of residues surrounding selected regions were performed using PyMOL (Molecular Graphics System, Version 2.3.0).

\section{Results}

NMDAR sensitivity to inhibitory neurosteroids increases following receptor stimulation in the presence of $\mathrm{Ca}^{2+}$

Endogenous neurosteroid PAS is an inhibitor of all major NMDAR isoforms (Park-Chung et al., 1994; Petrovic et al., 2005). In the course of our experiments, we have noticed that the degree of $50 \mu \mathrm{M}$ PAS inhibition of GluN1/GluN2B receptor response varied considerably (from $36.7 \%$ to $73.6 \%$; $n=81$ ), suggesting that an endogenous mechanism may affect the sensitivity of NMDARs to neurosteroids. Since NMDAR ion channels are $\mathrm{Ca}^{2+}$-permeant (MacDermott et al., 1986), we hypothesized that changes in intracellular $\mathrm{Ca}^{2+}$ concentration $\left(\left[\mathrm{Ca}^{2+}\right]_{\mathrm{i}}\right)$ may trigger an endogenous mechanism that affects the NMDAR sensitivity to steroids. Therefore, we assessed NMDAR sensitivity to the inhibitory effect of the steroid before and after a $\left[\mathrm{Ca}^{2+}\right]_{\mathrm{i}}$ increase. Shortly after attaining the whole-cell configuration (1-3 min), we measured the effect of the steroid on responses induced by $1 \mu \mathrm{M}$ glutamate in the presence of $0.2 \mathrm{~mm}\left[\mathrm{Ca}^{2+}\right]_{\mathrm{o}}$ (control response). Subsequently, $\left[\mathrm{Ca}^{2+}\right]_{\mathrm{i}}$ was increased by activating NMDARs by 1 mu glutamate in the presence of $2 \mathrm{~mm}\left[\mathrm{Ca}^{2+}\right]_{\mathrm{o}}$ for $50 \mathrm{~s}\left(\mathrm{Ca}^{2+}\right.$ challenge). The effect of the $\mathrm{Ca}^{2+}$ challenge on steroid inhibition was then tested on responses again induced by $1 \mu \mathrm{M}$ glutamate and recorded in the presence of $0.2 \mathrm{~mm}\left[\mathrm{Ca}^{2+}\right]_{\mathrm{o}}$ (test response) (Fig. 1). The control responses recorded in HEK cells expressing GluN1/GluN2B receptors were robustly inhibited by $100 \mu \mathrm{M}$ PAS $(58.5 \pm 2.1 \% ; n=5)$, but the test responses were even more sensitive to PAS inhibition $(74.1 \pm 3.3 \%$; $n=5)$ (Fig. $1 A)$. Consistent with stimulation-induced NMDAR inactivation (Rosenmund and Westbrook, 1993; Vyklicky, 1993), the maximal amplitude of the test responses was on average $30.6 \pm 1.7 \%(n=60)$ of the amplitude of the control responses.

A similar analysis of the inhibitory effect of synthetic PAS analogs $30 \mu \mathrm{M}$ PAhPim (Vyklicky et al., 2016) and $20 \mu \mathrm{M}$ ANDAsp (Adla et al., 2017) (Fig. 1A) showed that these steroids also inhibited the test responses more strongly than the control responses. The relative increase in the inhibitory effect at GluN1/ GluN2B receptors was 16\% for PAS, 52\% for PAhPim, and 14\% for ANDAsp. Similar, but stronger, effects were seen for the $\mathrm{Ca}^{2+}$ challenge in native NMDARs expressed in cultured hippocampal neurons activated by $10 \mu \mathrm{M}$ NMDA; this was particularly noticeable for PAhPim $(30 \mu \mathrm{M})$ that actually slightly potentiated the control responses, by $1.9 \pm 0.7 \%(n=6)$, while strongly inhibiting the test responses, by $61.9 \pm 3.3 \%(n=6)$ (Fig. $1 B)$. No increase in the inhibitory effect of PAhPim was observed for native AMPARs (Fig. 1B). Since the relative increase in the inhibitory effect was largest for PAhPim, this steroid was used in subsequent experiments.

To better characterize the effect of the $\mathrm{Ca}^{2+}$ challenge on the NMDAR sensitivity to steroid inhibition, we determined the dose-response relationship for the inhibition of GluN1/GluN2B receptors by PAhPim. The analysis indicated a leftward shift from $\mathrm{IC}_{50}=44.6 \pm 4.9 \mu \mathrm{M}(n=8)$ for the PAhPim inhibition of the control responses to $\mathrm{IC}_{50}=12.1 \pm 1.2 \mu \mathrm{M}(n=8)$ determined for the test responses (Fig. $1 C$ ). This was even more pronounced in cultured hippocampal neurons; at $30 \mu \mathrm{M}$, PAhPim had virtually no effect on control responses, while the test responses were inhibited with the $\mathrm{IC}_{50}=25.4 \pm 1.3 \mu \mathrm{M}(n=6)$ (Fig. 1D).

To examine the possibility that the consequences of the $\mathrm{Ca}^{2+}$ challenge for the NMDAR pharmacology might be because of prolonged NMDAR stimulation rather than an increase in the $\left[\mathrm{Ca}^{2+}\right]_{\mathrm{i}}$, we performed experiments in which the challenge was delivered in the absence of $\left[\mathrm{Ca}^{2+}\right]_{0}$ (in nominally $\mathrm{Ca}^{2+}$-free ECS). Under these conditions, PAhPim (30 $\mu \mathrm{M})$ inhibited the test responses induced in recombinant GluN1/GluN2B receptors significantly less (by $36.0 \pm 4.7 \% ; n=5$ ) than test responses recorded following the $\mathrm{Ca}^{2+}$ challenge in the presence of $2 \mathrm{~mm}$ $\left[\mathrm{Ca}^{2+}\right]_{\mathrm{o}}$ (by $\left.73.0 \pm 1.8 \% ; n=60\right)(p<0.001$; unpaired $t$ test).

We next considered whether the increase in the NMDAR sensitivity to PAhPim inhibition is directly dependent on the elevated $\left[\mathrm{Ca}^{2+}\right]_{i}$ or whether the transient rise in $\left[\mathrm{Ca}^{2+}\right]_{\mathrm{i}}$ activates downstream intracellular mechanisms that in turn modulate NMDAR inhibition by PAhPim. Figure 2 shows results of experiments in which $\mathrm{Ca}^{2+}$ imaging was used simultaneously with whole-cell patch-clamp recording. Despite intracellular dialysis with the $\mathrm{Ca}^{2+}$ chelator EGTA (5 mM) in the ICS, ratiometric $\mathrm{Ca}^{2+}$ imaging indicated a robust increase in the $\left[\mathrm{Ca}^{2+}\right]_{\mathrm{i}}$ during the $\mathrm{Ca}^{2+}$ challenge. This is expected since NMDAR ion channels are highly permeable to $\mathrm{Ca}^{2+}$ (MacDermott et al., 1986), EGTA is a relatively slow $\mathrm{Ca}^{2+}$ chelator (Stern, 1992), and the buffering capacity of $5 \mathrm{~mm}$ EGTA is not sufficient to fully buffer long-term $\mathrm{Ca}^{2+}$ influx. The fluorescence ratio (F340/F380) increased $>2$ fold during the $\mathrm{Ca}^{2+}$ challenge and then returned to control values within $\sim 2 \mathrm{~min}$ (Fig. 2 ). In contrast, the degree of PAhPiminduced inhibition of the test responses of GluN1/GluN2B receptors to glutamate was not appreciably changed regardless of the time (0.5-30 $\mathrm{min})$ after the $\mathrm{Ca}^{2+}$ challenge (Fig. 2). A relatively constant degree of PAhPim inhibition of test responses was apparent for measurements made during simultaneous voltageclamp recording and $\mathrm{Ca}^{2+}$ imaging (where the ICS contained fura), as well as for measurements from cells dialyzed with regular ICS (without fura). These experiments indicate that $\mathrm{Ca}^{2+}$ influx is required for the increased steroid-induced inhibition of the test responses. However, the increased NMDAR sensitivity to inhibitory steroid action outlasts the $\left[\mathrm{Ca}^{2+}\right]_{\mathrm{i}}$ increase, suggesting that the transient $\left[\mathrm{Ca}^{2+}\right]_{\mathrm{i}}$ increase triggers some intracellular mechanism that maintains the increased inhibition even after the $\left[\mathrm{Ca}^{2+}\right]_{\mathrm{i}}$ had returned to baseline levels.

\section{Increased NMDAR sensitivity to steroids depends on the CTD of the GluN2B subunit}

Given the role of the $\left[\mathrm{Ca}^{2+}\right]_{i}$ increase in modulating NMDAR sensitivity to inhibitory steroids, we focused on the intracellularly oriented CTD of GluN subunits, as the most likely structural target to mediate the effects of $\left[\mathrm{Ca}^{2+}\right]_{\mathrm{i}}$ signaling on NMDAR function. We used recombinant GluN1/GluN2B receptors with truncated CTD (GluN1(R839X) and GluN2B(R847X)). Control responses induced in GluN1(R839X)/GluN2B(R847X) receptors were profoundly inhibited by PAhPim $(30 \mu \mathrm{M})$, and the $\mathrm{Ca}^{2+}$ challenge did not increase the inhibition further. The degree of PAhPim inhibition of the control and the test GluN1(R839X)/ GluN2B(R847X) receptor responses was larger (by $24 \%$ and $23 \%$, respectively; $p<0.001$, unpaired $t$ test) than the inhibition of the test responses of GluN1/GluN2B(WT) receptors (Fig. 3). In a separate experiment, a second $\mathrm{Ca}^{2+}$ challenge in HEK cells expressing GluN1/GluN2B(WT) receptors increased PAhPiminduced inhibition beyond the level induced by the first $\mathrm{Ca}^{2+}$ challenge (by $6 \%-18 \%$ ), approaching the degree of steroid inhibition observed for GluN1(R839X)/GluN2B(R847X) receptors, suggesting that the combined GluN1 and GluN2B CTD truncation increases the inhibitory effect of the steroid to a maximum. In contrast, control responses induced in GluN1(R839X)/ GluN2B receptors were inhibited by PAhPim to the extent 

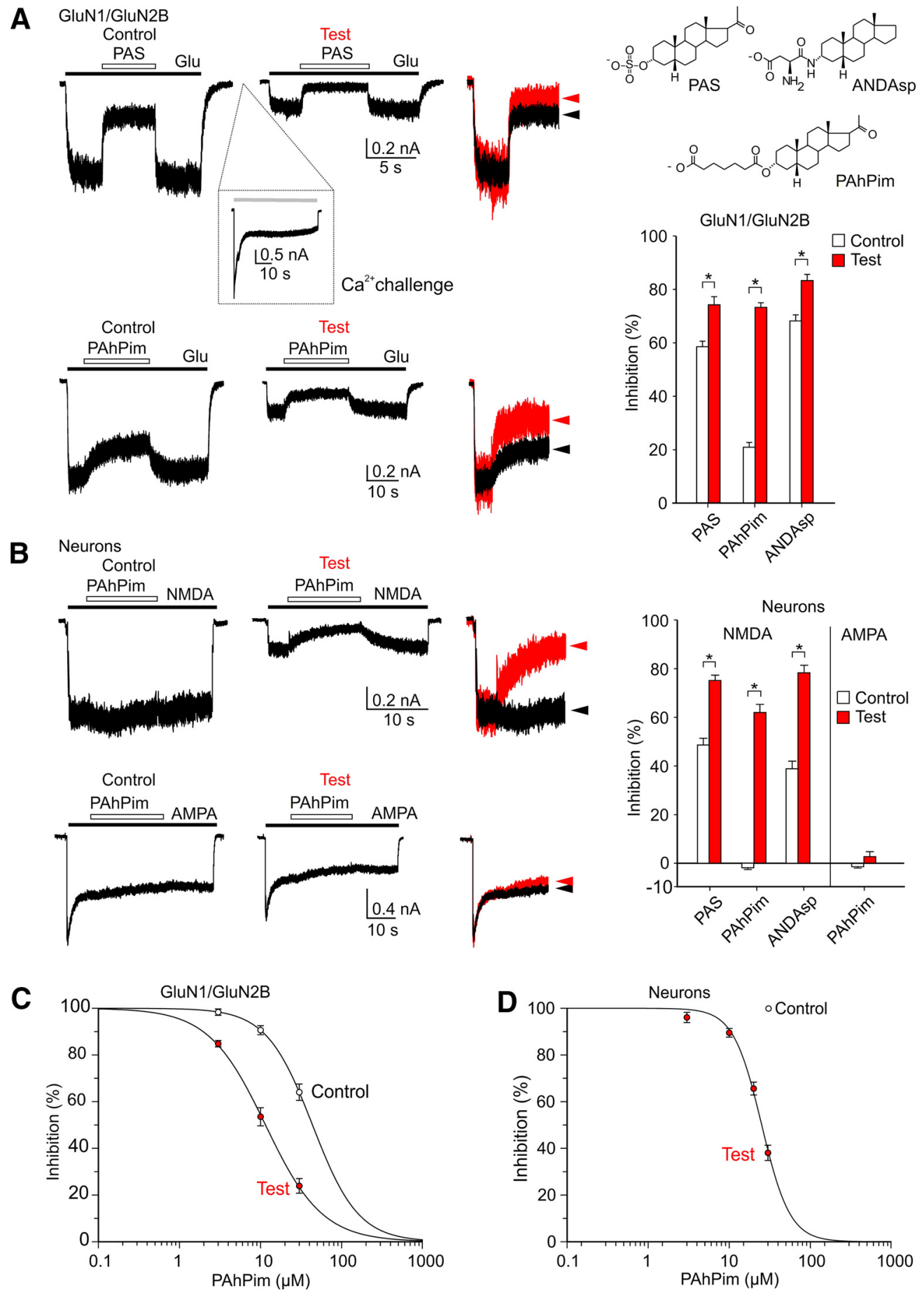

Figure 1. NMDAR apparent affinity for steroids is increased following the $\mathrm{Ca}^{2+}$ challenge. Examples of traces obtained from HEK cells expressing GluN1/GluN2B receptors $(\boldsymbol{A})$ and from cultured rat hippocampal neurons expressing native NMDARs and AMPARs $(\boldsymbol{B})$. PAS (100 $\mu \mathrm{m})$ and PAhPim were applied in the presence of $1 \mu \mathrm{m}$ glutamate $(\boldsymbol{A})$ or $10 \mu \mathrm{m}$ NMDA or $5 \mu \mathrm{m}$ AMPA (B). Open and filled bars represent the duration of the steroid and the agonist application, respectively, in the continuous presence of $0.2 \mathrm{~mm}\left[\mathrm{Ca}^{2+}\right]_{0}$ before (Control) and after (Test) the application of $1 \mathrm{~mm}$ glutamate $(\boldsymbol{A})$ or $100 \mu \mathrm{M}$ NMDA $(\boldsymbol{B})$ in the presence of $2 \mathrm{~mm}\left[\mathrm{Ca}^{2+}\right]_{0}\left(\mathrm{Ca}^{2+}\right.$ challenge is shown in $\boldsymbol{A}$, inset). Right, Control (black) and test (red) responses are displayed overlaid and normalized with respect to the current amplitude before the steroid application to show the difference in the steroid inhibitory effect. The structure of the steroids used is shown in $\boldsymbol{A}$ (top right corner). Bar graphs represent the inhibitory effect \pm SEM for PAS (100 $\mu \mathrm{M})$, PAhPim $(30 \mu \mathrm{M})$, and ANDAsp $(20 \mu \mathrm{M})$ on control (open bars) and test (red bars) responses determined in HEK cells expressing GluN1/GluN2B receptors $(\boldsymbol{A})$ and in cultured rat hippocampal neurons expressing native NMDA or AMPARs $(\boldsymbol{B})$. Data were statistically analyzed using paired $t$ tests. *Statistically significant difference between control and test responses (for details and $p$ values, see Extended Data Table 1-1). Dose-response analysis of the PAhPim (3-30 $\mu \mathrm{m}$ ) effect on the control and test responses recorded from recombinant GluN1/GluN2B receptors $(\boldsymbol{C})$ and the test responses recorded from native NMDARs in cultured hippocampal neurons $(\boldsymbol{D})$. Steroid-induced inhibition was fitted to Equation 3.

typical for the control GluN1/GluN2B(WT) receptor responses, and the inhibition of test GluN1(R839X)/GluN2B receptor responses increased as observed for the test GluN1/GluN2B (WT) receptor responses (Fig. 3). The effect of PAhPim in
GluN1/GluN2B(R847X) receptors was similar to the effect in GluN1(R839X)/GluN2B(R847X) receptors (Fig. 3A,B). These data indicate that the GluN2B CTD is critically involved in controlling NMDAR steroid sensitivity. 
The GluN2B CTD has been shown to bind various intracellular proteins, including postsynaptic density protein-95 (Kornau et al., 1995), calmodulin (Ehlers et al., 1996), and $\alpha$-actin (Wyszynski et al., 1997), and is the target of post-translational modification, including phosphorylation by multiple protein kinases at serine, threonine, and tryptophan residues (Traynelis et al., 2010), palmitoylated at two clusters of cysteines (Hayashi et al., 2009), and ubiquitinated at lysines (Jurd et al., 2008). To narrow down possible intracellular mechanisms that may control NMDAR steroid sensitivity, we analyzed the effect of PAhPim on recombinant GluN1/GluN2B receptors with the GluN2B CTD truncated to different lengths. As shown in Figure 4, the relative degree of PAhPim inhibition of control and test responses induced in receptors containing the GluN2B subunit truncated in the terminal region of the CTD (GluN1/GluN2B (Y1281X; Y1004X; E955X; I925X; and T888X)) was not significantly different from PAhPim inhibition determined in GluN1/ GluN2B(WT) receptors.

Using the same strategy, we proceeded to analyze the effect of PAhPim on receptors with longer truncations of the GluN2B CTD tail. The effect of PAhPim at GluN1/GluN2B (E878X) receptors was intermediate between the effect at WT receptors and those lacking the entire CTD (GluN1/GluN2B (R847X), with control responses being more inhibited by PAhPim compared with GluN1/GluN2B(WT) receptors, but the $\mathrm{Ca}^{2+}$ challenge induced increase in the PAhPim inhibitory effect similar to that observed for WT receptors (Fig. 4). The effect of PAhPim at GluN1/GluN2B(S870X; F862X; and C854X) was significantly different from the effect on GluN1/ GluN2B(WT) receptors and similar to PAhPim inhibition seen in receptors lacking the entire CTD (GluN1/GluN2B $(\mathrm{R} 847 \mathrm{X}))$. These results indicate that a stretch of 32 amino acid residues located in the juxtamembrane region of the GluN2B CTD (R847 to E878) is critical for the modulation of NMDAR sensitivity to inhibitory steroids.

The region of the CTD of the GluN2B subunit critical for controlling the NMDAR sensitivity to PAhPim inhibition (R847E878) contains three cysteine residues (C849, C854, and C871), which can be palmitoylated (Hayashi et al., 2009) (Fig. $5 A$ ). To test whether the NMDAR steroid sensitivity is affected by palmitoylation, we generated a triple mutant of the GluN2B subunit where all three cysteines (C849, C854, and C871) were mutated to nonpalmitoylable alanine GluN2B(AAA). Unlike GluN1/GluN2B(WT) receptors, where the $\mathrm{Ca}^{2+}$ challenge increases steroid inhibition, control responses evoked in cells expressing the nonpalmitoylable mutant were already profoundly inhibited by PAhPim $(30 \mu \mathrm{M})$ and the $\mathrm{Ca}^{2+}$ challenge increased the degree of inhibition only slightly (Fig. 5B,C). To test the importance of each of the three relevant cysteine residues, we produced a set of three mutants where the individual cysteines were mutated to alanine: C849A (GluN2B(ACC)), C854A (GluN2B(CAC)), and C871A (GluN2B (CCA)). PAhPim inhibited the control responses of GluN1/GluN2B(ACC) and

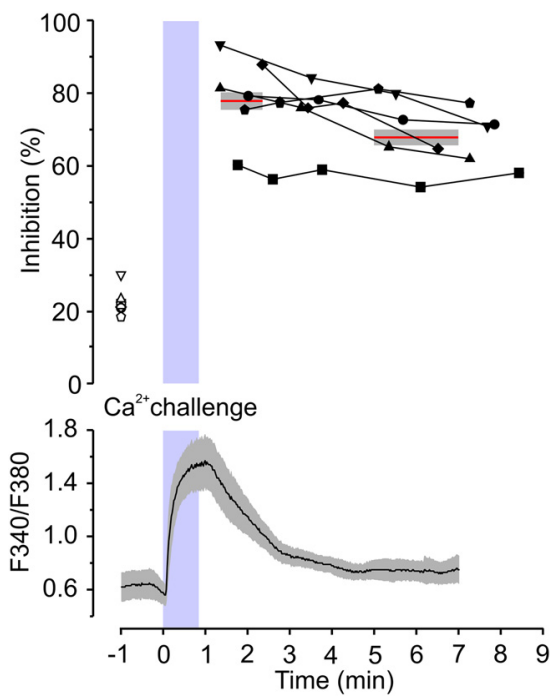

Figure 2. Increased GluN1/GluN2B receptor sensitivity to PAhPim is induced by increased $\left[\mathrm{Ca}^{2+}\right]_{i}$, but its maintenance is $\mathrm{Ca}^{2+}$-independent. Simultaneous $\mathrm{Ca}^{2+}$ imaging and glutamate-evoked current recording was used to monitor changes in $\left[\mathrm{Ca}^{2+}\right]_{i}$ and the degree of PAhPim inhibition (for details, see Materials and Methods). The relative degree of PAhPim (30 $\mu \mathrm{m}$ ) inhibition of control (open symbols) and test (filled symbols) responses of GluN1/ GluN2B receptors is plotted as a function of time (symbols represent individual cells) (top). Blue rectangle represents the duration of the $\mathrm{Ca}^{2+}$ challenge. fura fluorescence ratio F340/ F380 acquired at the frequency of $1 \mathrm{~Hz}$ was assessed before, during, and after the $\mathrm{Ca}^{2+}$ challenge. Graph represents mean (black line) \pm SEM (gray area) F340/F380 values ( $n=6$ ) (bottom). Mean PAhPim inhibition (red line) \pm SEM (gray area) at 1.3-2.3 min (steroid application immediately after the $\mathrm{Ca}^{2+}$ challenge when $\mathrm{F} 340 / \mathrm{F3} 30$ was maximal; $77.8 \pm 4.7 \%$ ) and at 5-7 min (when F340/F380 was again at baseline levels; $67.9 \pm 4.2 \%$; $n=6)$. The degree of inhibition was not significantly different between these time periods (paired $t$ test; $p=0.059$ ).

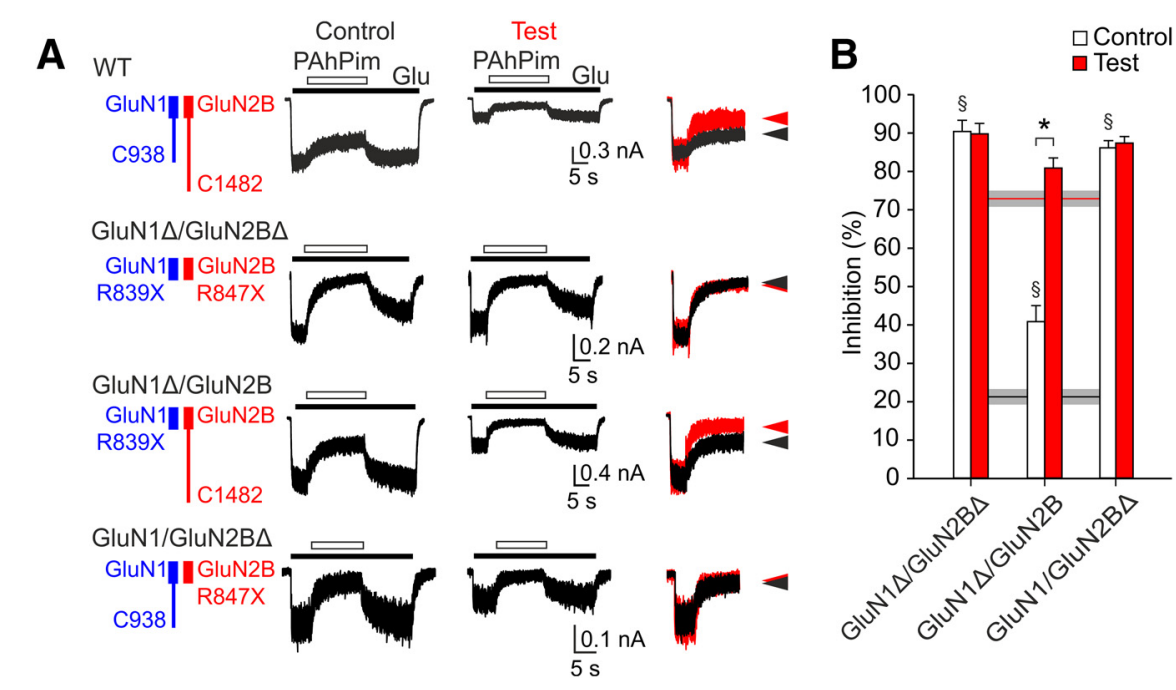

Figure 3. Increased NMDAR sensitivity to PAhPim is dependent on the CTD of the GluN2B subunit. $\boldsymbol{A}$, Examples of traces obtained from HEK cells expressing GluN1/GluN2B(WT), GluN1(R839X)/GluN2B(R847X), GluN1(R839X)/GluN2B, and GluN1/ GluN2B(R847X) receptors. PAhPim (30 $\mu \mathrm{m}$ ) was applied in the presence of glutamate (1 $\mu \mathrm{m})$. Open and filled bars represent the time of PAhPim and glutamate application, respectively. Right, Control (black) and test (red) responses are displayed overlaid and normalized with respect to the current amplitude before the steroid application to show the difference in the steroid inhibitory effect. Left, Diagrams represent the membrane topology and the truncation of the receptor. $\boldsymbol{B}$, Bar graph represents the relative degree of PAhPim ( $30 \mu \mathrm{m}$ ) inhibition of the control and the test responses evoked by $1 \mu \mathrm{m}$ glutamate in WT (black and red horizontal lines, respectively, \pm SEM in gray) or in truncated GluN1/GluN2B receptors. Data are mean PAhPim-induced inhibition in \% $\%$ SEM. *Statistically significant difference between control versus test responses. $\S$ Statistically significant difference between the control response recorded from receptors lacking GluN1 and/or GluN2B CTD versus WT (for details and $p$ values, see Extended Data Table 3-1). 
A

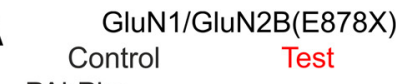

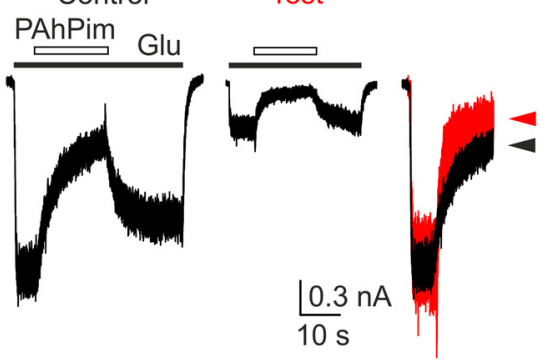

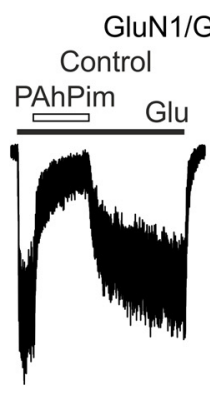

GluN1/GluN2B(S870X) Test

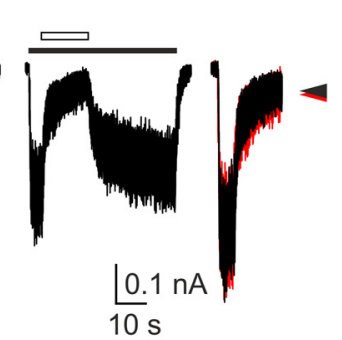

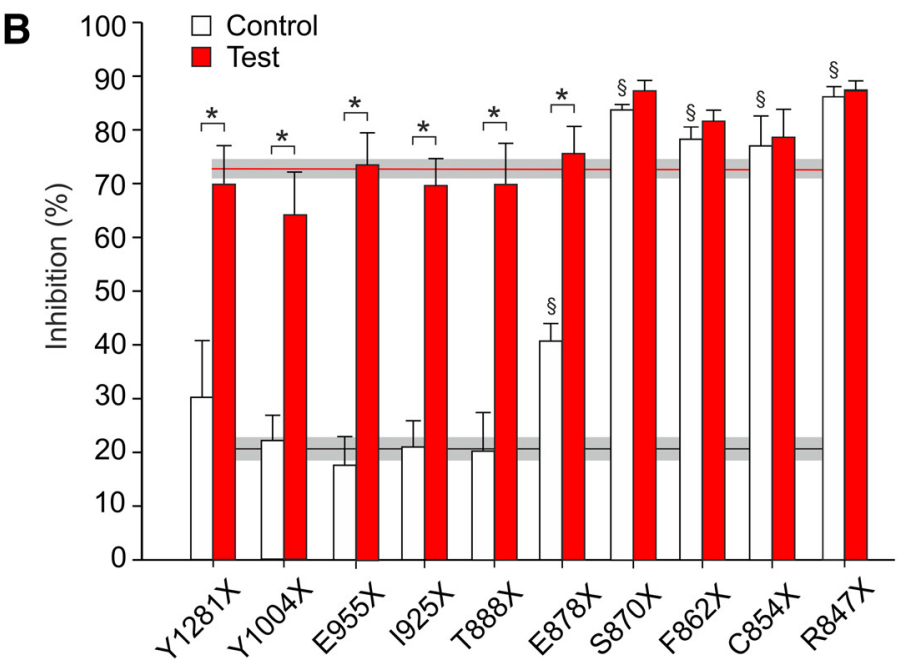

Figure 4. A region in the GluN2B CTD adjacent to the M4 helix is critical for controlling NMDAR steroid sensitivity. $A$, Examples of traces obtained from HEK cells expressing GluN1/GluN2B(E878X) and GluN1/GluN2B(S870X) receptors. PAhPim $(30 \mu \mathrm{M})$ was applied in the presence of glutamate $(1 \mu \mathrm{M})$. Open and filled bars represent the duration of steroid and glutamate application, respectively. Right, Control (black) and test (red) responses are displayed overlaid and normalized with respect to the current amplitude before the steroid application to show the difference in the steroid inhibitory effect. $\boldsymbol{B}, \mathrm{Bar}$ graph represents the relative degree of PAhPim $(30 \mu \mathrm{m})$ inhibition of control and test responses to $1 \mu \mathrm{m}$ glutamate induced in WT (black and red horizontal lines, respectively, \pm SEM in gray), or truncated GluN1/GluN2B receptors. Data are mean PAhPim-induced inhibition in \% $\%$ SEM. *Statistically significant difference between control versus test responses.

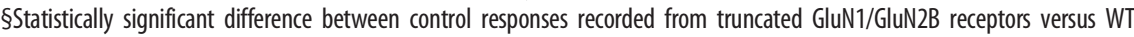
(for details and $p$ values, see Extended Data Table 4-1).

GluN1/GluN2B(CCA) receptors to the same extent as test responses of WT receptors. The control responses of GluN1/ GluN2B(CAC) receptors were inhibited by the steroid to a degree that was intermediate between that observed for control responses of the GluN1/GluN2B(WT) and the GluN1/ GluN2B(AAA) receptors (Fig. 5C). In addition, we have performed experiments in which PAhPim sensitivity was determined in receptors containing a partially truncated GluN2B CTD and the cysteines C849, C854, and C871 mutated to alanine (GluN1/GluN2B(AAA, E878X)). Steroid sensitivity of these receptors was similar to that observed for receptors containing a full-length GluN2B CTD with the three cysteines mutated to alanines (GluN1/GluN2B(AAA)). These data indicate that the mechanism involved in the increased NMDAR sensitivity to inhibitory steroids following the $\mathrm{Ca}^{2+}$ challenge depends on the palmitoylation of the cysteine residues located in the juxtamembrane region and, further, that the disruption of just one palmitoylation site (any of C849, C854, or C871) increases NMDAR steroid sensitivity.

We hypothesized that the increased NMDAR sensitivity to inhibitory steroids may occur as a consequence of receptor depalmitoylation triggered by $\left[\mathrm{Ca}^{2+}\right]_{\mathrm{i}}$ and/or that palmitoylation-dependent CTD interaction with the plasma membrane is disrupted following an increase in $\left[\mathrm{Ca}^{2+}\right]_{\mathrm{i}}$ by a mechanism that does not involve depalmitoylation. To distinguish between these possibilities, we used tunicamycin, a nucleoside antibiotic that, because of its structural similarity with palmitoyl CoA, can inhibit protein palmitoylation within hours (Patterson and Skene, 1995). HEK cells expressing GluN1/GluN2B(WT) receptors were treated for 1-2 $\mathrm{h}$ before electrophysiological experiments with $1.2 \mu \mathrm{m}$ tunicamycin. The inhibition of control responses by PAhPim in tunicamycin-treated HEK cells $(48.3 \pm 5.9 \% ; n=10)$ was significantly greater than in tunicamycinuntreated cells $21.1 \pm 1.9 \% ; n=60$ ) (Fig. $5 D$ ); thus, we conclude that palmitoylation influences the NMDAR sensitivity to inhibitory neurosteroids.

\section{Effects of palmitoylation on the functional properties of the NMDAR channel}

To investigate the effects of palmitoylation on the gating properties, we performed long-duration cell-attached recording from HEK cells expressing GluN1/GluN2B(WT) or GluN1/GluN2B(AAA) receptors. For each receptor type, we obtained steady-state single-channel current recordings containing only one active channel. Inward currents were obtained in the presence of saturating concentrations of glutamate (1 $\mathrm{mm})$ and glycine $(0.1 \mathrm{~mm})$, at a physiological proton concentration, $\mathrm{pH} 7.3$, and in the absence of divalent cations (1 mM EDTA). Both receptor genotypes produced unitary currents of uniform amplitudes, with no obvious sublevel conductances (Fig. 6A). Accumulated single-channel data were used to estimate channel $\mathrm{P}_{\mathrm{o}}$, mean open time, and mean closed time, as global characteristics of the gating kinetics (Table 1). The most striking change was observed for the $\mathrm{P}_{\mathrm{O}}$ that was diminished by $\sim 50 \%$ in GluN1/GluN2B (AAA) receptors. We also noticed a trend toward longer closures in mutated receptors; however, the difference in the mean closed time did not achieve statistical significance.

To investigate in further detail how the mutation of palmitoylable cysteines (C849, C854, C871) to alanines influences the NMDAR gating kinetics, we examined the distributions of event durations observed for mutated and WT receptors (Fig. 6B-G). Previous work established that NMDARs have complex open and closed event duration distributions (Gibb and Colquhoun, 1991). Openings of GluN1/GluN2B(WT) and GluN1/GluN2B (AAA) receptor channels distribute to four components $\left(\mathrm{T}_{\mathrm{O} 1}\right.$, $\left.\mathrm{T}_{\mathrm{O} 2 \text { low }}, \mathrm{T}_{\mathrm{O} 2 \text { medium }}, \mathrm{T}_{\mathrm{O} 2 \text { high }}\right)$. These reflect the two obligatory components present in each mode $\left(\mathrm{T}_{\mathrm{O} 1}\right.$ and $\left.\mathrm{T}_{\mathrm{O} 2}\right)$, with additional multiplicity resulting from the distinct durations of $\mathrm{T}_{\mathrm{O} 2}$ in each mode ( $\mathrm{T}_{\mathrm{O} 2 \text { low, }} \mathrm{T}_{\mathrm{O} 2 \text { medium }}$, and $\mathrm{T}_{\mathrm{O} 2 \text { high }}$ ) (Banke and Traynelis, 2003; Popescu and Auerbach, 2003; Popescu et al., 2004; Amico-Ruvio and Popescu, 2010) (Fig. 6B,C,F). The time constant of the $\mathrm{T}_{\mathrm{O} 2 \mathrm{low}}$ component $\left(\tau_{\mathrm{O} 2 \mathrm{low}}\right)$ was significantly shortened (by 65\%) in the activity recorded from GluN1/ 
GluN2B(AAA) receptors. Other time constants of open time distribution components $\left(\tau_{\mathrm{O} 1}, \tau_{\mathrm{O} 2 \text { medium }}\right.$, and $\left.\tau_{\mathrm{O} 2 \mathrm{high}}\right)$ and the relative areas of the individual components $\left(\mathrm{A}_{\mathrm{O} 1}-\mathrm{A}_{\mathrm{O} 2 \mathrm{high}}\right)$ in GluN1/ GluN2B(AAA) receptors had WT-like values (Fig. 6C; Table 2).

The closings of GluN1/GluN2B(WT) and GluN1/GluN2B(AAA) receptor channels distribute to five components: three shorter components $\left(\mathrm{T}_{\mathrm{C1}}-\mathrm{T}_{\mathrm{C} 3}\right)$ that represent mostly closings within bursts, and two longer components $\left(\mathrm{T}_{\mathrm{C} 4}\right.$ and $\left.\mathrm{T}_{\mathrm{C} 5}\right)$ that represent mostly long-term closings between bursts (desensitized states) (Fig. $6 D-F)$. The time constants of the $\mathrm{T}_{\mathrm{C} 2}$ and $\mathrm{T}_{\mathrm{C} 3}$ components $\left(\tau_{\mathrm{C} 2}\right.$ and $\left.\tau_{\mathrm{C} 3}\right)$, that represent the majority of closings within bursts, were significantly prolonged (5-fold and 3 -fold, respectively) in the activity recorded from GluN1/GluN2B(AAA) receptors. The time constants belonging to the $\mathrm{T}_{\mathrm{C} 1}, \mathrm{~T}_{\mathrm{C} 4}$, and $\mathrm{T}_{\mathrm{C} 5}$ components $\left(\tau_{\mathrm{C} 1}, \tau_{\mathrm{C} 4}\right.$, and $\left.\tau_{\mathrm{C} 5}\right)$, and the relative areas of the individual components $\mathrm{A}_{\mathrm{C} 1}-\mathrm{A}_{\mathrm{C} 5}$ in GluN1/ GluN2B(AAA) receptors had WT-like values (Fig. 6E; Table 3).

Next, we fit the entire sequence of events observed in each record with a linear model comprised of five closed (C1C5) and four open (O1-O4) states. The kinetic modeling indicated that, compared with GluN1/GluN2B(WT) receptors, gating changes were observed for GluN1/GluN2B(AAA) receptors (Fig. $6 F)$. The most pronounced rate changes concerned decelerated rate constants among individual liganded states with the channel closed (C3-C1), particularly the rates $\mathrm{C} 3 \rightarrow \mathrm{C} 2$ (2.9-fold decrease) and $\mathrm{C} 3 \leftarrow \mathrm{C} 2$ (4.7-fold decrease); in addition, the resensitization rate constant $(\mathrm{C} 5 \rightarrow$ C3) was also slowed (2.2-fold). In contrast, rate constants leading from the open state $(\mathrm{O} 2)$ were accelerated, particularly the rates $\mathrm{O} 2 \rightarrow \mathrm{O} 3$ (3.5-fold) and $\mathrm{O} 1 \leftarrow \mathrm{O} 2$ (1.7-fold). These results show that mutations that abolish palmitoylation at sites located at the GluN2B CTD in the proximity of the TMD have complex consequences for the NMDAR channel gating properties, generally favoring reduced channel activity.

Since neurosteroids are use-dependent NMDAR inhibitors (Petrovic et al., 2005; Vyklicky et al., 2015), the change in the PAhPim inhibitory effect following the $\mathrm{Ca}^{2+}$ challenge may be indirect, resulting from the altered receptor channel $\mathrm{P}_{\mathrm{o}}$ because of depalmitoylation (Table 1) and/or inactivation of the NMDAR (Legendre et al., 1993). To exclude the possibility that the change in the $P_{o}$ alone underlies the increased NMDAR steroid sensitivity following the $\mathrm{Ca}^{2+}$ challenge we: (1) assessed the effect of PAhPim on control and test responses evoked by $0.55 \mu \mathrm{m}$ glutamate, a concentration
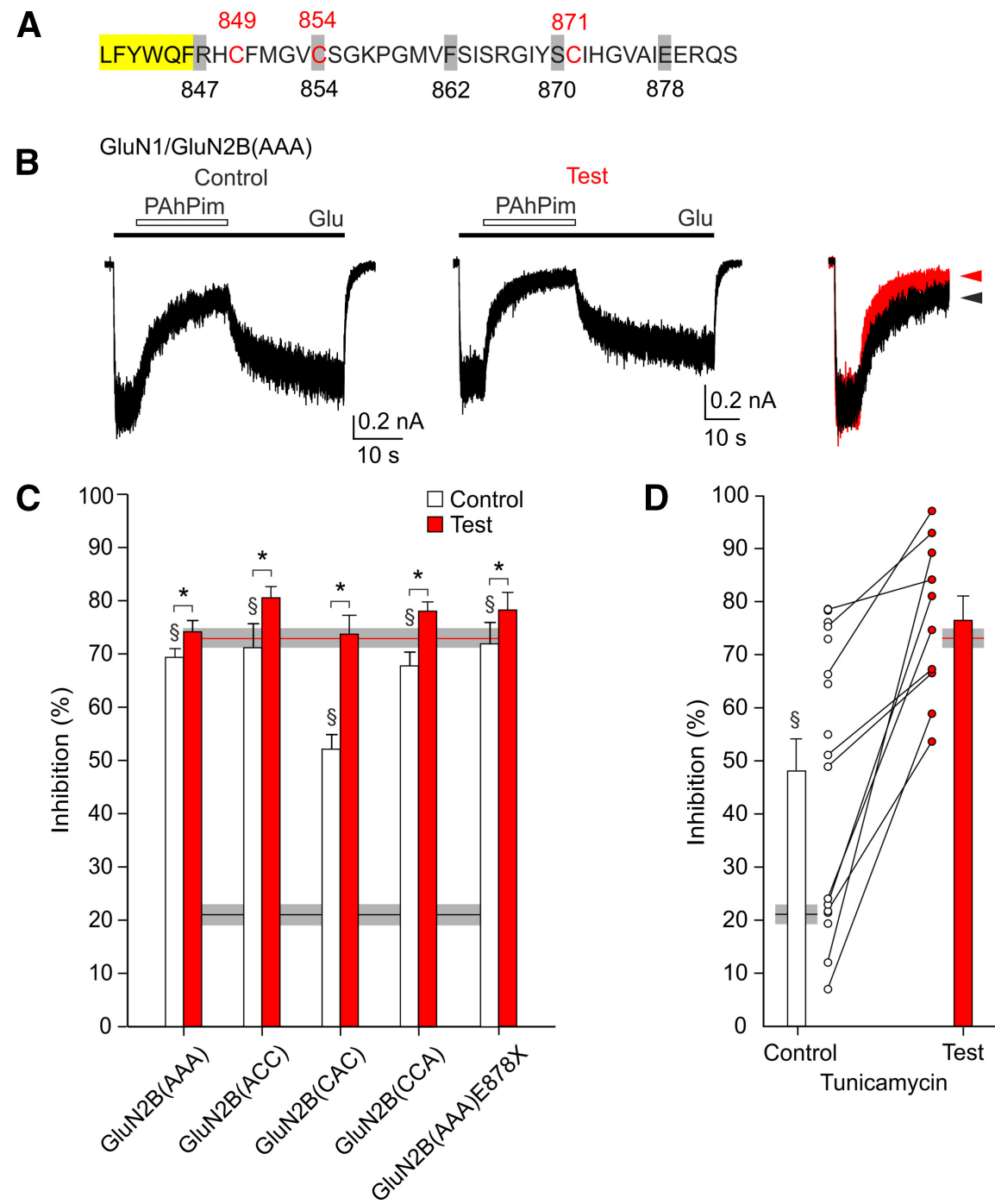

Figure 5. Receptors with the GluN2B subunit mutated at palmitoylation sites have increased steroid sensitivity. $\boldsymbol{A}$, Amino acid sequence of a portion of the M4 helix and the membrane-proximal region of the GluN2B subunit CTD. Yellow represents the membrane region. Gray represents the sites at which the CTD was truncated (labeled below). Red represents palmitoylated cysteines. $\boldsymbol{B}$, Example of a control and a test response from GluN1/GluN2B(AAA) receptors. PAhPim (30 $\mu \mathrm{m})$ was applied in the presence of glutamate $(1 \mu \mathrm{m})$. Open and filled bars represent the duration of steroid and glutamate application, respectively. Right, Control (black) and test (red) responses are displayed overlaid and normalized with respect to the current amplitude before the steroid application to show the difference in the steroid inhibitory effect. $\boldsymbol{C}$, Bar graph represents the relative degree of PAhPim (30 $\mu \mathrm{m}$ ) inhibition of control and test responses to $1 \mu \mathrm{m}$ glutamate induced in WT (black and red horizontal lines, respectively, \pm SEM in gray), or mutated GluN1/GluN2B receptors. Substitutions of cysteine with alanine are marked in parentheses and correspond to substitutions of $(849 \mathrm{~A}$, C854A, and/or C871A, respectively. Cysteine substitutions were created also in the truncated GluN2B(E878X) subunit; data for GluN1/GluN2B(AAA, E878X) receptors are shown; additional mutations are listed in Extended Data Table 5-1. D, Bar graph represents the relative degree of PAhPim (30 $\mu \mathrm{m}$ ) inhibition of control and test responses to $1 \mu \mathrm{m}$ glutamate in tunicamycin-treated HEK cells. Data are mean steroid inhibition in $\% \pm \mathrm{SEM}$. Horizontal lines indicate the mean PAhPim inhibition of control (black line \pm SEM in gray) and test (red line \pm SEM in gray) responses in tunicamycin-untreated cells (same data as shown in C). *Statistically significant difference between control versus test responses. $\S$ Statistically significant difference between control responses recorded from mutated GluN1/GluN2B receptors versus WT (for details and $p$ values, see Extended Data Table 5-1).

resulting in $\sim 50 \%$ GluN1/GluN2B receptor activation compared with $1 \mu \mathrm{M}$ glutamate; and (2) examined receptors mutated in the linker region (GluN1(I664G)/GluN2B) that have the $\mathrm{P}_{\mathrm{o}}$ diminished to $3.5 \pm 0.6 \%(n=4)$, and receptors mutated in the TMD $\left(\right.$ GluN1/GluN2B(V821A)) that have the $\mathrm{P}_{\mathrm{o}}$ reduced to $6.5 \pm$ $0.3 \%(n=4)$, compared with GluN1/GluN2B(WT) receptors that have the $\mathrm{P}_{\mathrm{o}}=9.7 \pm 2.8 \%(n=24)$ (Hrcka Krausova et al., 2020). Figure 7 shows that neither the reduced glutamate concentration nor the mutations reducing the $\mathrm{P}_{\mathrm{o}}$ affected the PAhPim 
A

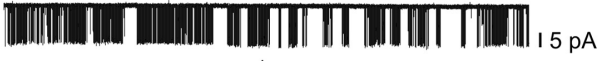

$100 \mathrm{~ms}$

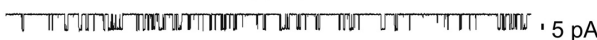

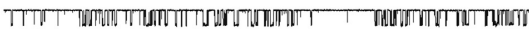

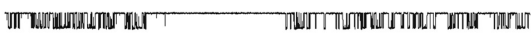

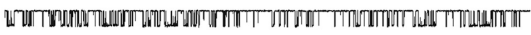

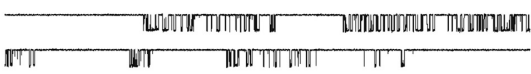

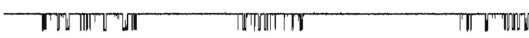

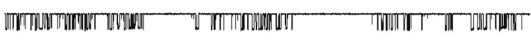

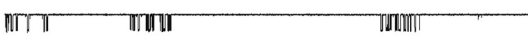

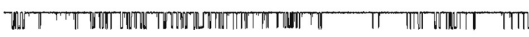

GluN1/GluN2B(AAA)

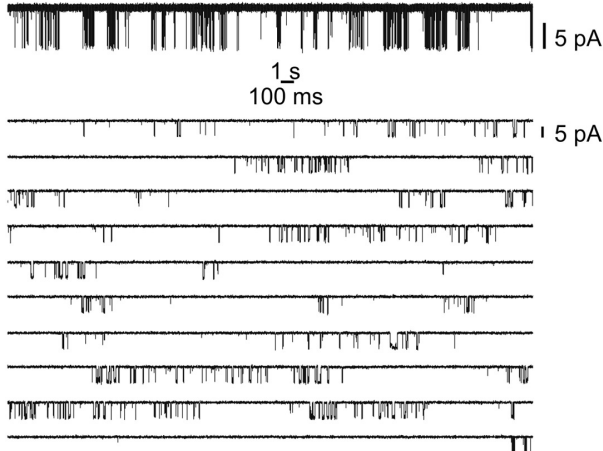

B

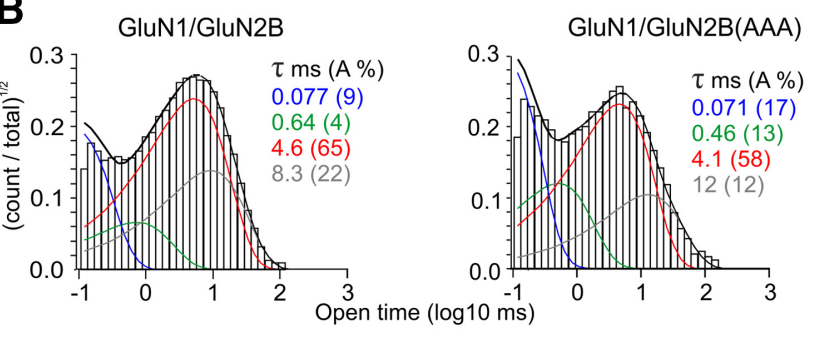

C

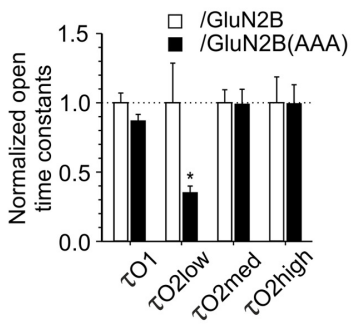

D GluN1/GluN2B
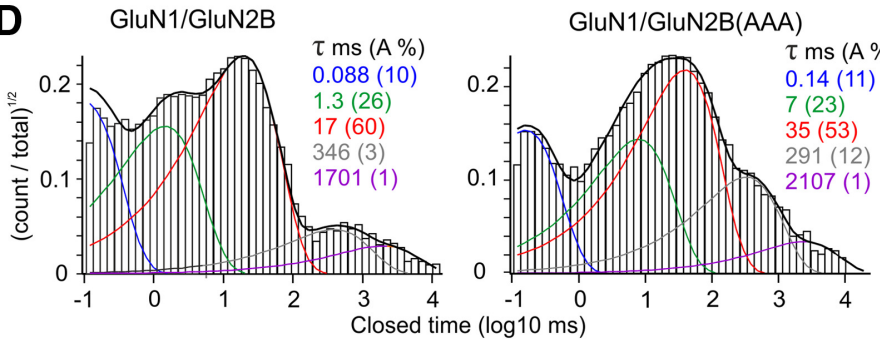

E

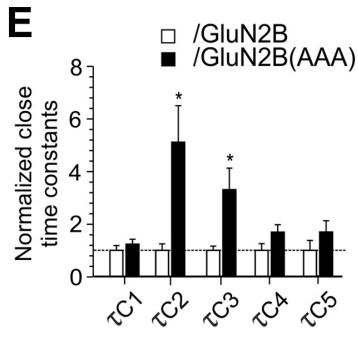

$\mathbf{F}$

GluN1/GluN2B

$\underset{0.70 / 1.4}{\mathrm{C} 3} \frac{13 / 8.8}{230} \mathrm{C} 2 \frac{340}{5300} \mathrm{C} 1 \frac{6800}{14000} \mathrm{O} 1 \frac{6100}{560} \mathrm{O} 2 \frac{460}{900} \mathrm{O} 3 \frac{39}{133} \mathrm{O} 4$

G

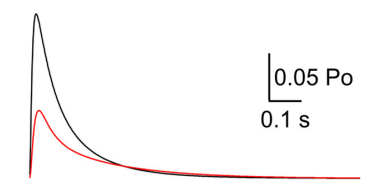

GluN1/GluN2B(AAA)

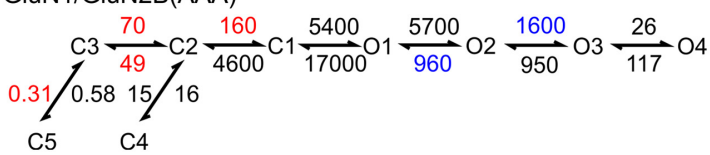

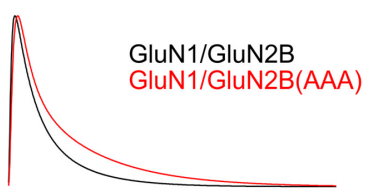

Figure 6. Effects of NMDAR palmitoylation on gating. $A$, Representative steady-state recordings of continuous single-channel activity in HEK cell-attached patches expressing GluN1/GluN2B (WT) or GluN1/GluN2B(AAA) receptors. Unitary currents (downward deflections) were activated by $1 \mathrm{~mm}$ glutamate and $100 \mu \mathrm{m}$ glycine at a pipette potential of $100 \mathrm{mV}$ (estimated holding potential $-130 \mathrm{mV}$ ). Data are shown on two different time scales. Open $(B, C$ and closed $(\boldsymbol{D}, \boldsymbol{E})$ duration distributions of single GluN1/GluN2B(WT) and GluN1/GluN2B(AAA) receptor channels. Overlaid are probability density functions (thick lines) and individual kinetic components (thin lines). Insets, Calculated time constants ( $\tau$ (ms)) and areas (A (\%)) for each component in a corresponding color code. Summary bar graph represents the relative changes in the duration of open $(\boldsymbol{C})$ and closed $(\boldsymbol{E})$ time constants (for the absolute values of the open and closed time constants, see Tables 2 and 3, respectively). *Statistically significant difference between GluN1/GluN2B(AAA) versus WT ( $p<0.05$; unpaired $t$ test). $\boldsymbol{F}$, Kinetic models optimized by fits to the entire sequence of closed and open intervals in each record; for each transition, rate constants (in $\mathrm{s}^{-1}$ ) are given as means: GluN1/GluN2B(WT), $n=10 ;$; GluN1/GluN2B(AAA), $n=9$. Blue represents rate constants showing a significant increase relative to $\mathrm{GluN1} / \mathrm{GluN2B(WT)}$. Red represents rate constants showing a significant decrease relative to $\mathrm{GluN1} / \mathrm{GluN2B}(\mathrm{WT}$ ). $p<0.05$ (paired $t$ test). All states $(C, 0)$ represent fully glutamate- and glycine-liganded receptors. $\mathbf{G}$, Macroscopic responses to $10 \mathrm{~ms}$ applications of $1 \mathrm{~mm}$ glutamate were simulated with the model in $\boldsymbol{F}$ (top, absolute scale; bottom, normalized to the peak amplitude). Rate constants for glutamate binding/unbinding (additional two states before (3) were $k_{b}=6 \mu \mathrm{m}^{-1} \cdot \mathrm{s}^{-1}$ and $k_{u}=15 \mathrm{~s}^{-1}$ (AmicoRuvio and Popescu, 2010).

Table 1. Effects of alanine substitution of palmitoylatable cysteines $\left(\mathbf{C 8 4 9}, \mathbf{C 8 5 4}, \mathbf{C 8 7 1 )}\right.$ of the GluN2B subunit on global kinetic properties of individual receptors ${ }^{\mathrm{a}}$

\begin{tabular}{|c|c|c|c|c|c|c|}
\hline & $P_{0}$ & Mean open time (ms) & Mean closed time (ms) & Amplitude (pA) & Total events & $\bar{n}$ \\
\hline GluN1/GluN2B(WT) & $0.10 \pm 0.02$ & $4.5 \pm 0.4$ & $83 \pm 29$ & $8.7 \pm 0.5$ & $2 \times 10^{5}$ & 10 \\
\hline GluN1/GluN2B(AAA) & $0.045 \pm 0.011^{*}$ & $4.5 \pm 0.5^{* *}$ & $159 \pm 39 \dagger$ & $7.5 \pm 0.4 \dagger \dagger$ & $9 \times 10^{4}$ & 9 \\
\hline
\end{tabular}

${ }^{a}$ Data are mean \pm SEM; $n$ is the number of patches recorded from.

Significant difference versus the WT receptor (unpaired $t$ test): ${ }^{*} p=0.032 ;{ }^{* *} p=1.000 ; t p=0.131 ;+\uparrow p=0.082$. 
Table 2. Effects of alanine substitution of palmitoylatable cysteines $\left(\mathbf{C 8 4 9}, \mathbf{C 8 5 4}, \mathbf{C 8 7 1 )}\right.$ of the GluN2B subunit on open-time intervals ${ }^{\mathrm{a}}$

\begin{tabular}{|c|c|c|c|c|c|}
\hline & $\tau_{01}(\mathrm{~ms})\left(\mathrm{A}_{01}\right)(\%)$ & $\tau_{021 \text { low }}(\mathrm{ms})\left(\mathrm{A}_{021 \mathrm{low}}\right)(\%)$ & $\tau_{02 \mathrm{med}}(\mathrm{ms}) \mathrm{A}_{02 \mathrm{med}}(\%)$ & $\tau_{02 \text { high }}(\mathrm{ms}) \mathrm{A}_{02 \text { high }}(\%)$ & $n$ \\
\hline GluN1/GluN2B (WT) & $\begin{array}{l}0.070 \pm 0.005 \\
\quad(12.6 \pm 1.2)\end{array}$ & $\begin{array}{c}1.137 \pm 0.325 \\
(11.0 \pm 3.7)\end{array}$ & $\begin{array}{r}4.585 \pm 0.430 \\
\quad(56.4 \pm 6.8)\end{array}$ & $\begin{array}{r}12.756 \pm 2.378 \\
(20.1 \pm 7.6)\end{array}$ & 10 \\
\hline GluN1/GluN2B(AAA) & $\begin{array}{r}0.061 \pm 0.003 * \\
(13.0 \pm 1.1) \ddagger\end{array}$ & $\begin{array}{r}0.398 \pm 0.056 * * \\
(12.5 \pm 0.7) \text { 㧊 }\end{array}$ & $\begin{array}{l}4.530 \pm 0.500 \dagger \\
\quad(57.1 \pm 5.2) \S\end{array}$ & $\begin{array}{r}12.654 \pm 1.759 \dagger \dagger \\
(17.5 \pm 5.2) \S \S\end{array}$ & 9 \\
\hline
\end{tabular}

${ }^{a}$ Data are mean \pm SEM; $n$ is the number of patches recorded from.

Significant difference versus the WT receptor (unpaired $t$ test): $* p=0.152 ; * * p=0.049 ; \nmid p=0.934 ; \dagger t p=0.973 ; \neq p=0.810 ; \neq \neq p=0.710 ; \S p=0.937 ; \S \S p=0.786$.

Table 3. Effects of alanine substitution of palmitoylatable cysteines $\left(\mathbf{C 8 4 9 ,}\right.$ (854, C871) of the GluN2B subunit on closed time intervals ${ }^{\mathrm{a}}$

\begin{tabular}{|c|c|c|c|c|c|c|}
\hline & $\tau_{\mathrm{C} 1}(\mathrm{~ms})\left(\mathrm{A}_{\mathrm{C} 1}\right)(\%)$ & $\tau_{\mathrm{C} 2}(\mathrm{~ms}) \mathrm{A}_{\mathrm{C} 2}(\%)$ & $\tau_{\mathrm{C3}}(\mathrm{ms}) \mathrm{A}_{\mathrm{C3}}(\%)$ & $\tau_{C 4}(\mathrm{~ms}) \mathrm{A}_{C 4}(\%)$ & $\tau_{C 5}(\mathrm{~ms}) \mathrm{A}_{C 5}(\%)$ & $n$ \\
\hline GluN1/GluN2B (WT) & $\begin{array}{r}0.143 \pm 0.026 \\
\quad(11.9 \pm 1.4)\end{array}$ & $\begin{array}{l}3.22 \pm 0.78 \\
(17.5 \pm 4.1)\end{array}$ & $\begin{array}{l}26.5 \pm 4.2 \\
\quad(57.1 \pm 5.7)\end{array}$ & $\begin{array}{l}364 \pm 92 \\
\quad(12.0 \pm 3.5)\end{array}$ & $\begin{array}{r}3537 \pm 1321 \\
(1.5 \pm 0.6)\end{array}$ & 10 \\
\hline GluN1/GluN2B(AAA) & $\begin{array}{r}0.176 \pm 0.027 * \\
\quad(12.1 \pm 1.4) \ddagger\end{array}$ & $\begin{array}{l}16.44 \pm 4.47 * * \\
\quad(34.8 \pm 7.8) \neq \neq\end{array}$ & $\begin{array}{l}87.4 \pm 21.7 \dagger \\
\quad(38.7 \pm 6.7) \S\end{array}$ & $\begin{array}{l}614 \pm 103+\dagger \\
\quad(13.4 \pm 3.1) \S \S\end{array}$ & $\begin{array}{c}5991 \pm 1519+\mathrm{t \dagger} \\
(1.0 \pm 0.2) \|\end{array}$ & 9 \\
\hline
\end{tabular}

${ }^{a}$ Data are mean \pm SEM; $n$ is the number of patches recorded from.

Significant difference versus the WT receptor (unpaired $t$ test): $* p=0.391 ; * * p=0.007 ; \dagger p=0.010 ; \dagger+p=0.087 ; \dagger+\uparrow p=0.237 ; \neq p=0.921 ; \neq \neq p=0.059 ; \S p=0.051 ; \S \S p=0.770 ; \| p=0.460$.

inhibition of control and test responses compared with GluN1/ GluN2B(WT) receptors activated by $1 \mu \mathrm{m}$ glutamate. These data suggest that the underlying reason for the observed increase in the PAhPim inhibitory effect following the $\mathrm{Ca}^{2+}$ challenge are palmitoylation/depalmitoylation-dependent structural changes in the receptor.

\section{Effect of palmitoylation on CTD interaction with the membrane}

Our experimental results indicate that palmitoylation of three cysteines (C849, C854, and C871) in the intracellular CTD of the receptor affects NMDAR affinity for PAhPim, binding at a site located at the extracellular channel vestibule (Vyklicky et al., 2015). We hypothesized that palmitoylation could: (1) induce structural changes of the otherwise intrinsically disordered juxtamembrane region of the GluN2B CTD; (2) influence the interaction of the juxtamembrane region of the GluN2B CTD with the membrane; and (3) related to both points above, induce changes in the M4 helix structure or dynamics affecting the role of the M4 helix within the TMD. To elucidate the structural consequences of GluN2B CTD palmitoylation, we used all-atom MD simulations of a model system of the M4-E878X segment of the GluN2B subunit, containing the M4 helix extended by the juxtamembrane region of the GluN2B CTD immersed in a model membrane. Our MD results indicated that palmitoylated as well as nonpalmitoylated M4-E878X CTD segments were spending most of the simulation time in contact with the membrane surface and adopting a relatively extended conformation. In simulations starting with the palmitoyl moieties pointing into the solution, we observed a fast reorientation of the aliphatic tails and their incorporation into the membrane, reaching the final orientation aligned with the phospholipid hydrophobic tails within $<100$ ns (Fig. $8 A$ ). This orientation was then stable during the rest of the simulation, and no dissociation was observed at the simulation time scale. The positions of the terminal palmitoyl aliphatic carbons and $\mathrm{C} \alpha$ atoms of the cysteine residues with or without palmitoylation are shown relative to the membrane thickness in Figure $8 B-D$. The flipping of the palmitoylated cysteine residues when entering the membrane was compensated by the flexibility of neighboring residues and did not induce any significant structural changes of the M4 helix. The nonpalmitoylated M4-E878X CTD segment showed higher mobility and
A

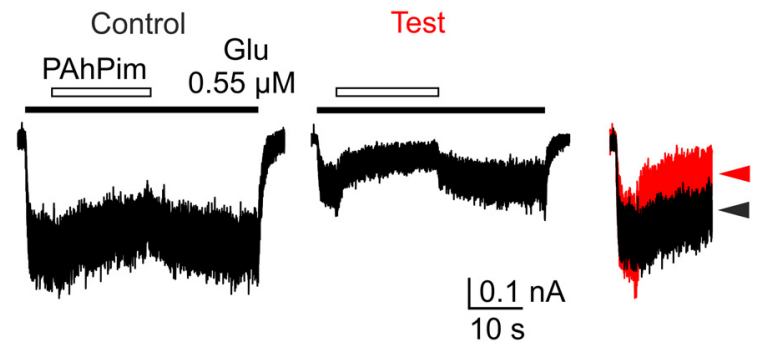

B

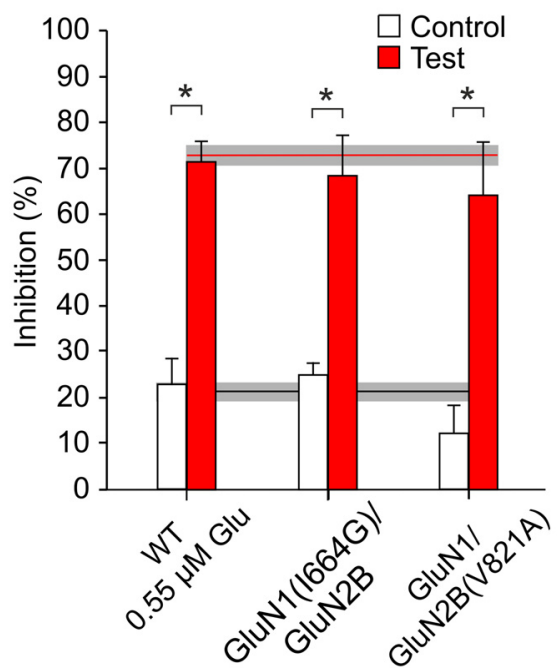

Figure 7. Analysis of the effect of low $P_{0}$ on the GluN1/GluN2B receptor sensitivity to PAhPim. A, Examples of currents from GluN1/GluN2B(WT) receptors. PAhPim (30 $\mu \mathrm{m}$ ) was applied in the presence of glutamate $(0.55 \mu \mathrm{m})$. Open and filled bars represent the duration of steroid and glutamate application, respectively. Right, Control (black) and test (red) responses are displayed overlaid and normalized with respect to the current amplitude before the steroid application to show the difference in the steroid inhibitory effect. $\boldsymbol{B}$, Bar graph represents the inhibitory effect of PAhPim $(30 \mu \mathrm{m})$ on control and test responses induced by $0.55 \mu \mathrm{m}$ glutamate in GluN1/GluN2B(WT) receptors and in mutated receptors (GluN1/GluN2B (V821A); GluN1/GluN2B(I664G)) activated by $1 \mu \mathrm{m}$ glutamate. Data are mean PAhPiminduced inhibition in \% \pm SEM. Horizontal lines indicate the degree of PAhPim-induced inhibition of control (black) and test (red) responses induced in GluN1/GluN2B(WT) receptors by $1 \mu \mathrm{m}$ glutamate. Gray areas represent the SEM. * Statistically significant difference between control versus test responses (paired $t$ test) (for details and $p$ values, see Extended Data Table 7-1). 
A
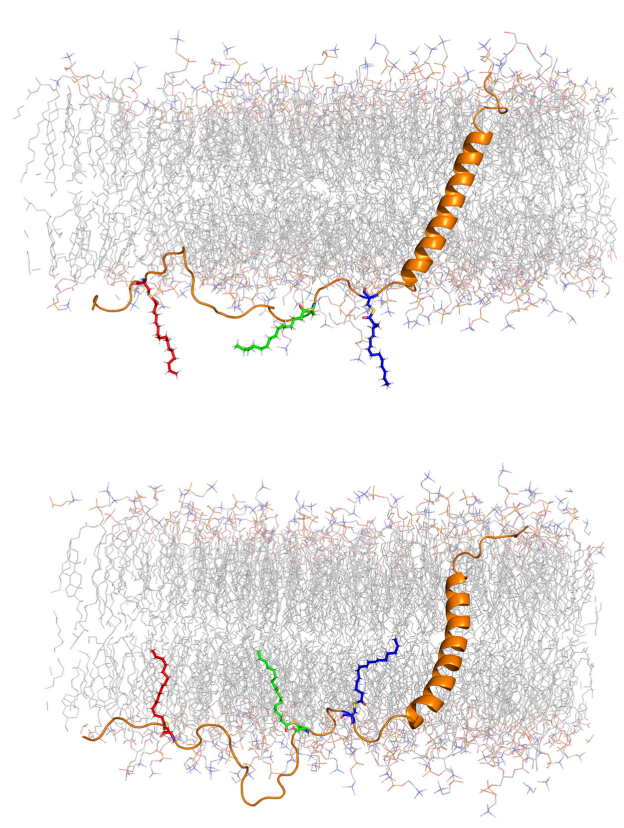

$\mathbf{E}$

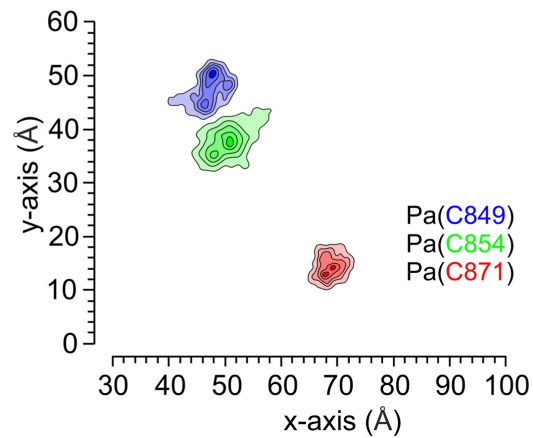

B

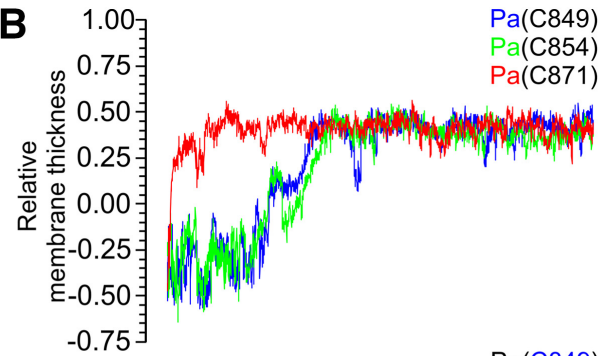

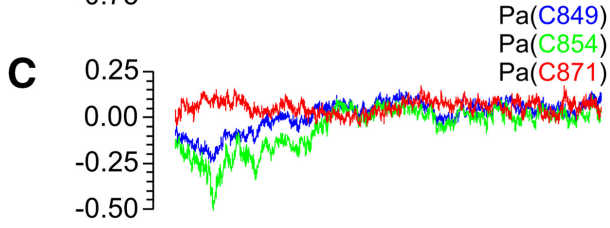

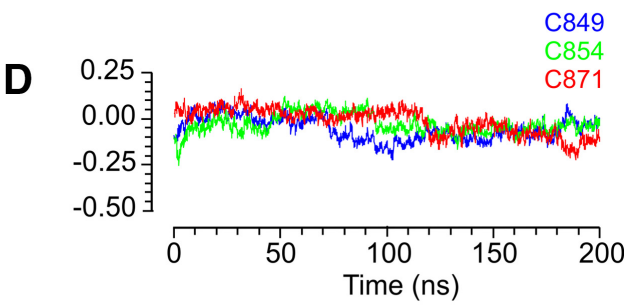

$\mathbf{F}$

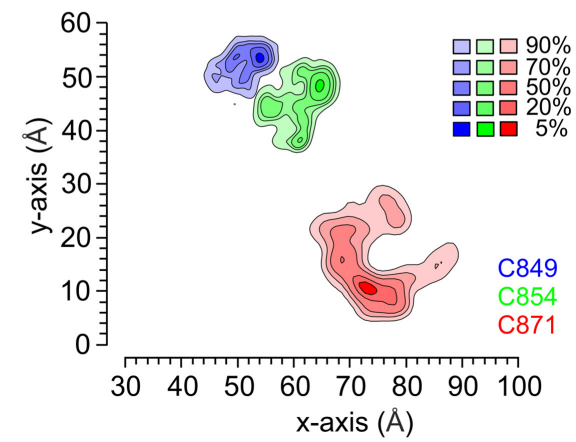

Figure 8. In silico analysis of the structural consequences of CTD palmitoylation. $\boldsymbol{A}$, Typical orientation of palmitoylated cysteine residues (C849 in blue, C854 in green, C871 in red) before (top) and after (bottom) the MD simulation of the palmitoylated M4-E878X CTD segment (orange diagram) in the model membrane shown as lines (carbon in gray, oxygen in red, and nitrogen in blue). The positions of the terminal palmitoyl aliphatic $(\mathrm{Pa})$ carbons $(\boldsymbol{B})$ and $(\alpha$ atoms of cysteine residues with $(\boldsymbol{C})$ or without $(\boldsymbol{D})$ palmitoylation are shown relative to the membrane thickness. The $y$ coordinates 0.00 and 1.00 represent the relative average position of phosphates of the lower and the upper membrane leaflet, respectively. Value of 0.50 indicates the lipophilic center of the membrane, and values outside of the 0 -1 interval indicate the solvent phase. $\boldsymbol{E}$, $\boldsymbol{F}$, The projection of the palmitoylated $(\boldsymbol{E})$ or the nonpalmitoylated $(\boldsymbol{F})$ M4-E878X (TD segment cysteine residue $C \alpha$ positions to the membrane plane during the MD simulation. Color shades represent the percentage of simulation time spent in the given locations.

larger lateral displacements projected to the plane of the membrane compared with the much less mobile palmitoylated M4E878X CTD segment (Fig. 8E,F).

\section{NMDAR sensitivity to steroids in stressed cells}

To examine possible physiological consequences of the $\mathrm{Ca}^{2+}$ induced increase in NMDAR sensitivity to inhibitory steroids, we examined the effects of PAhPim on NMDAR-mediated excitotoxicity in primary hippocampal cultures (Fig. 9). Applying NMDA directly to the media leads to neuronal cell death that is mediated primarily by $\mathrm{Ca}^{2+}$-dependent mechanisms (Choi et al., 1988). We hypothesized that, if NMDARs undergo a change in the steroid sensitivity during the excitotoxic challenge, similar to what we see in whole-cell recording following the $\mathrm{Ca}^{2+}$ challenge, then PAhPim will have a neuroprotective effect, particularly under more severe conditions.

As expected, NMDA, in a dose-dependent manner, increased the number of cells stained by PI, a marker of cell death. Bath application of $3 \mu \mathrm{M}$ NMDA did not increase the percentage of PI-positive neurons over control; but following the application of 10 or 30 $\mu \mathrm{M}$ NMDA, the percentage of PI-positive neurons was significantly increased. PAhPim $(30 \mu \mathrm{M})$ had no effect on cell death in the absence of NMDA or in the presence of lower NMDA concentrations of 3 or $10 \mu \mathrm{M}$ (Extended Data Table 9-1). However, when coapplied with $30 \mu \mathrm{M}$ NMDA, PAhPim significantly reduced the percentage of PI-positive neurons (Fig. 9). While our experiments do not address the question of whether endogenous neurosteroids are indeed present before and/or during the excitotoxic insult, our result with exogenously applied synthetic steroid is consistent with our electrophysiological observations that large $\mathrm{Ca}^{2+}$ influx through NMDAR channels increases the receptor sensitivity to inhibitory steroids. Interestingly, this $\mathrm{Ca}^{2+}$-dependent feedback mechanism of NMDAR subunit palmitoylation/depalmitoylation could act "on demand" to increase the inhibitory effect of neurosteroid-based NMDAR modulators to render them neuroprotective against NMDAR-mediated cell injury and excitotoxicity when needed, without unwanted side effects under physiological conditions.

\section{Discussion}

The results reported here show that the NMDAR sensitivity to inhibitory neurosteroids is controlled by palmitoylation at 

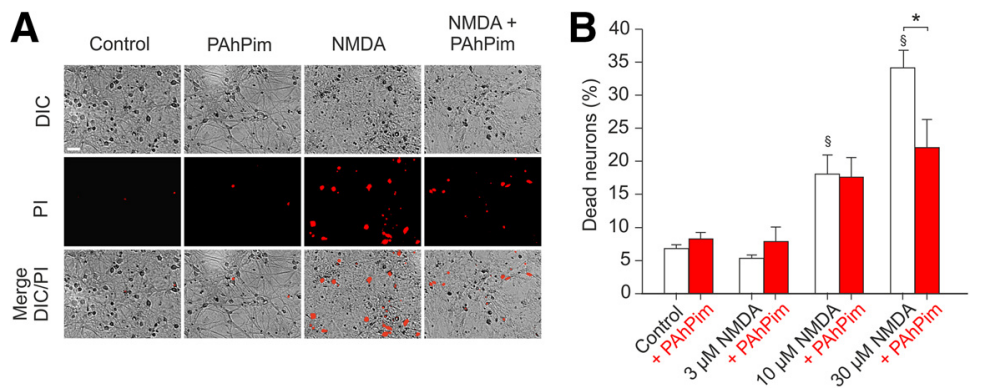

Figure 9. PAhPim is neuroprotective against NMDA-induced excitotoxicity. A, Representative images of PI-stained cultures treated with control media, $30 \mu \mathrm{m}$ PAhPim, $30 \mu \mathrm{m}$ NMDA, or 30 $\mu \mathrm{m} \mathrm{NMDA}+30 \mu \mathrm{m}$ PAhPim. Scale bar, $50 \mu \mathrm{m}$. B, Bar graph represents the percentage of dead neurons counted as the number of Pl-positive nuclei normalized to the total number of neuronal nuclei identified from the $\mathrm{H}$ staining (see Materials and Methods). *Statistically significant difference between the percentage of dead neurons assessed in NMDA-treated cultures versus cultures treated with NMDA + PAhPim. §Statistically significant difference between the percentage of dead neurons assessed in control media-treated cultures versus cultures treated with different concentrations of NMDA (for details and $p$ values, see Extended Data Table 9-1).

Rattus norvegicus
GluN1
GluN2A

Figure 10. Amino acid sequence alignment of the M4 domain and the proximal region of the CTD across rat glutamate receptor subunits. Shown are the NMDA subtype rat GluN subunits, AMPA subtype rat GluA subunits, and kainate subtype rat GluK subunits. The numbering is for the mature protein. The CTDs of all subunits are truncated. The portion of the M4 helix facing intracellularly (yellow) and cysteines (red) are shown.

cysteine residues located in the CTD of the GluN2B subunit. Depalmitoylation is triggered by a rise in $\left[\mathrm{Ca}^{2+}\right]_{\mathrm{i}}$; and in addition to steroid sensitivity, it has consequences for the NMDAR channel $\mathrm{P}_{\mathrm{o}}$.

Systematic CTD truncation and single-amino acid substitution experiments have led to the identification of three cysteine residues located in the juxtamembrane region of the GluN2B CTD that are critically involved in the control of the NMDAR function and sensitivity to inhibitory steroids. These cysteines were previously found to be palmitoylated (Hayashi et al., 2009). Palmitoylation is a reversible post-translational modification that results in the addition of a 16-carbon saturated fatty acyl chain to cytoplasmic cysteine residues (Conibear and Davis, 2010). At the cellular level, this protein modification promotes protein folding, targeting, membrane tethering, trafficking, localization into specific membrane domains, and proper orientation within the membrane (Charollais and Van Der Goot, 2009). Protein palmitoylation has been described for many cytosolic and membranebound proteins, including ligand-gated ion channels: AMPARs (Hayashi et al., 2005), kainate receptors (Pickering et al., 1995), NMDARs (Hayashi, 2020), GABA $\mathrm{A}$ receptors (Rathenberg et al., 2004), and P2X7 receptors (Gonnord et al., 2009).

Studies conducted on NMDARs suggest that the GluN1 subunit does not undergo palmitoylation, while the GluN2A and GluN2B subunits have two separate clusters of CTD cysteine residues that can be palmitoylated. The first cluster in the proximity of the M4 segment increases nearby tyrosine phosphorylation by Src family kinases, regulating surface expression and receptor internalization, and the second cluster is associated with the accumulation of NMDARs in the Golgi apparatus and decreased surface expression (Hayashi et al., 2009; Hayashi, 2020). Similarly, AMPAR GluA1 subunit has two known palmitoylation sites, one in the M2 membrane domain that, when palmitoylated, increases receptor surface expression, and the second one in the CTD that, when palmitoylated, reduces receptor surface expression and PKC-mediated phosphorylation (Lin et al., 2009; Hayashi, 2020). The homomeric GluK2 kainate receptor undergoes palmitoylation at its CTD cysteine residues C827 and C840, and this modulates PKC-mediated phosphorylation of the receptor without affecting basal receptor function (Pickering et al., 1995). Sequence alignment of the ionotropic glutamate receptor family shows that GluN2A-D, GluA1, GluK1, and GluK2 subunits contain palmitoylable cysteines (http://csspalm.biocuckoo. org/), indicating that receptors containing these subunits may undergo similar structural rearrangements when depalmitoylated as we show for GluN1/GluN2B receptors. In contrast, GluN1, GluN3A, GluA2, and GluA3 subunits do not contain cysteine residues in the juxtamembrane region (Fig. 10).

Our MD simulation (Fig. 8) shows rapid palmitoyl interaction with the cytoplasmic membrane resulting in only subtle effects on the CTD structure and/or its interaction with the adjacent receptor domains. To elucidate the molecular mechanism whereby the palmitoyl-mediated anchoring of the CTD could promote changes in the pharmacology and gating of the receptor (Figs. 1, 6), we took advantage of our recently described model of the NMDAR transition from the ion channel open state to the relaxed unliganded state where the channel is closed. This transition is accompanied by large rearrangements, of which the most prominent is the LBD and the TMD counterrotation around the longitudinal axis of the receptor (Cerny et al., 2019). Since the 

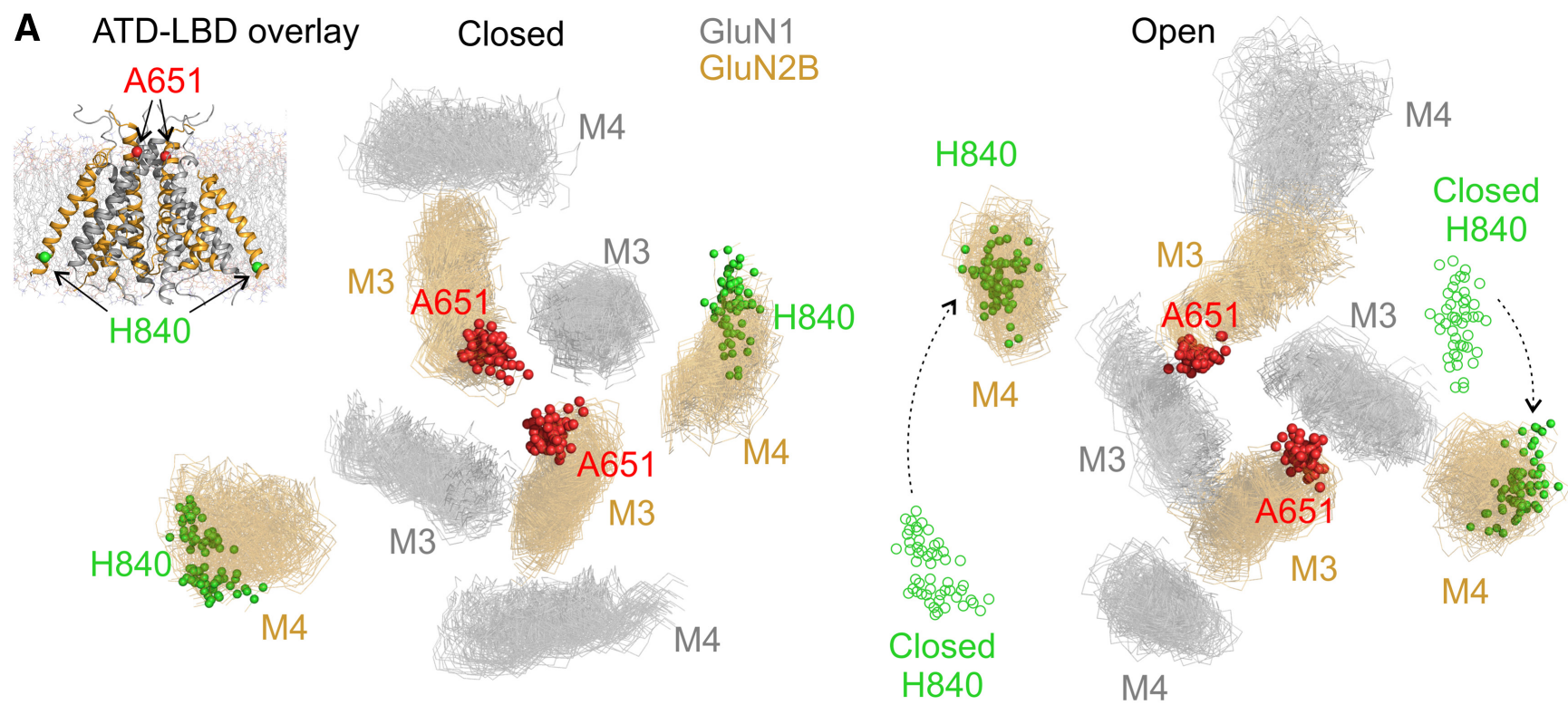

\section{B M4 overlay}
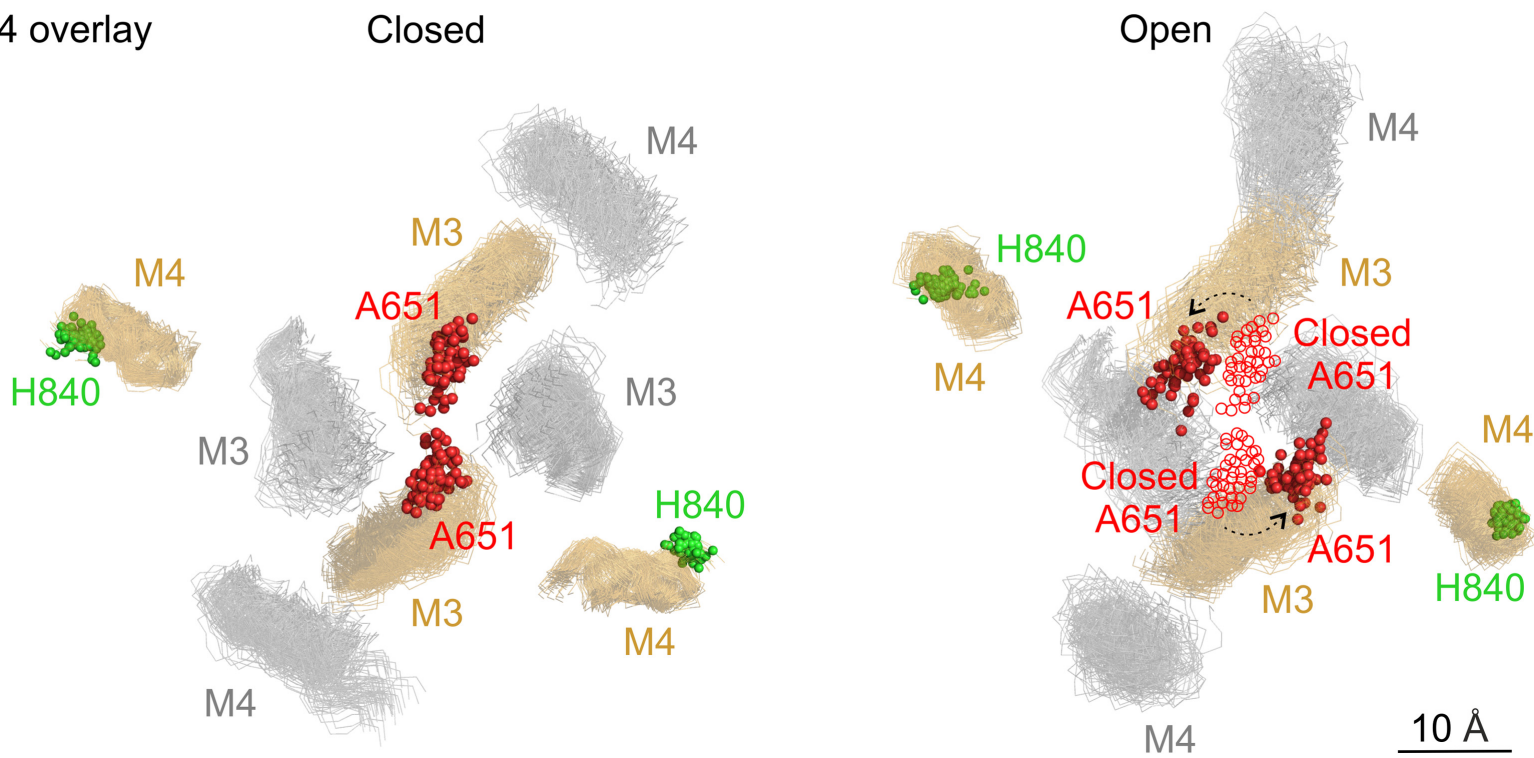

Figure 11. Structural features of NMDAR channel opening. Models of the GluN1/GluN2B receptor TMD (GluN1 in gray, GluN2B in orange) with extracellular segments of the M3 helices represented by the $C \alpha$ atoms of GluN2B A651, indicated by red spheres, and the intracellular portion of the M4 helices represented by the C $\alpha$ atoms of GluN2B H840, indicated by green spheres (see $\boldsymbol{A}$, inset). $\boldsymbol{A}$, Structural snapshots of the GluN1/GluN2B TMD in gray/orange stick backbone representation (viewed from the extracellular side) with the NMDAR in the nonactivated state with the channel closed (Closed, left) and activated with the channel open (Open, right). The snapshots were selected from an aggregate of nearly $1 \mu$ s of unbiased all-atom implicit membrane and solvent MD simulations of the structural transition from the closed to the open state of the NMDAR (for details, see Cerny et al., 2019). Both structures were aligned with respect to the ATD and the LBD and are shown separately for display purposes. Right, Empty green circles represent the position of the GluN2B H840 residue ensemble in the corresponding closed state. Dashed line with arrowhead indicates the movement of the M4 helices during the opening transition. $\boldsymbol{B}$, Structural snapshots of the TMD (viewed from the extracellular side) with the NMDAR in the nonactivated state with the channel closed (Closed, left) and activated with the channel open (Open, right). Both structures were aligned with respect to the GluN2B M4 helices and are shown separately for display purposes. Right, Empty red circles represent the position of the GluN2B A651 residue ensemble in the corresponding closed state. Dashed line with arrowhead indicates the movement of the $\mathrm{M} 3$ helices during the opening transition.

simulations were performed with the receptor without the full CTD and using an implicit membrane description, it is difficult to determine the extent of the actual relative rotation of the TMD with respect to the $\mathrm{LBD}$ or vice versa.

Figure 11 illustrates two extreme cases. The first case assumes that the ATD and the LBD domains are fixed and only the TMD is allowed to rotate. To understand the motivation for this scenario, it is worth noting that the TMD molecular mass is more than sixfold lower than that of the extracellular domains (the difference is even larger when accounting for glycosylation). It is quite likely that, in contrast to the compact structures of the ATD, LBD, and TMD, the mostly intrinsically disordered GluN2B subunit CTD (Ryan et al., 2008) will have a much lower stabilizing effect despite its large mass. When comparing the masses of the extracellular domains with the CTD, the extracellular part is still $>1.4$-fold heavier. To visualize the movements of the TMD during its transition from the closed state to the open state, we took the MD snapshots belonging to previously 
assigned Markov states (Cerny et al., 2019) and we aligned them with respect to the extracellular part of the receptor. This alignment highlights two structural consequences in the TMD: The intracellular segments of the GluN2B M4 helices, represented by GluN2B(H840), move around the $z$ axis in an interval of $0^{\circ}-74^{\circ}$, corresponding to a displacement of $0^{\circ}-38 \AA$. In contrast, the extracellular segments of the M3 (the site of the channel gate), represented by GluN2B(A651), occupy the same space for both the open and the closed state (Fig. 11A). This indicates that the ion channel gate opens rather reluctantly when the CTD is not anchored to the membrane.

The second case assumes that the M4 will be fixed and the LBD with the ATD will rotate. This mimics palmitoylated receptor, where the palmitoyls anchor the M4 helices to the membrane. To visualize the movements of the TMD during the closed-to-open transition, the MD simulation snapshots were aligned with respect to the intracellular segments of the GluN2B M4 helices. The position of several M3 and M4 amino acids is shown in Figure $11 B$. This analysis reveals a quarter-of-the-turn rotation of the extracellular segments of the M3 helices of the GluN1 and GluN2B subunits (Fig. 11B), representing an iris-like motion of the M3 helices occurring during the channel transition from the closed to the open state (Kazi et al., 2014; Cerny et al., 2019). This model stresses the importance of relatively fixed M4 helices for the operation of the NMDAR as a molecular machine. Palmitoylation-mediated anchoring of the juxtamembrane portion of the CTD may thus provide an important additional TMD stabilizing factor. Further, the MD simulation is consistent with the idea that the loss of the CTD anchoring may change the structure or accessibility of the extracellular channel vestibule (extracellular M3 segments) recognized as the inhibitory steroid site of action (Vyklicky et al., 2015).

The results of the single-channel analysis support the role of the CTD anchoring in the gating mechanisms of GluN1/GluN2B (WT) and GluN1/GluN2B(AAA) receptors (Fig. 6). Changes in both the open and the closed time distributions indicate that depalmitoylated receptors have a lower $\mathrm{P}_{\mathrm{o}}$, and kinetic models derived from this allowed us to predict macroscopic responses to brief pulses of glutamate that reproduce responses of synaptic receptors. The results showed that GluN1/GluN2B(AAA) receptors produced currents with the peak amplitude diminished by $59 \%$ and the weighted deactivation slowed by $54 \%$ (Fig. $6 G$ ). The role of palmitoylation in NMDAR gating described here may provide an alternative explanation of the functional changes observed in NMDARs with CTD truncations (Maki et al., 2012; Punnakkal et al., 2012; Iacobucci and Popescu, 2020).

Although there are numerous studies concerning the role of palmitoylation in the control of channel cell-surface expression and spatial organization (Shipston, 2011; Lussier et al., 2015), relatively few studies have described effects of palmitoylation on intrinsic activity and/or gating kinetics of ion channels. Palmitoylation of the voltage-sensitive potassium channel $\mathrm{Kv}-1.1$ increases the intrinsic voltage sensitivity of the channel (Gubitosi-Klug et al., 2005), whereas the palmitoylated regulatory $\beta 2$ a subunit of the $\mathrm{N}$-type calcium channel controls voltage-dependent inactivation (N. Qin et al., 1998). Recently, it has been shown that NMDAR potentiation by docosahexaenoic acid was reduced in GluN1/GluN2A receptors with alanine substitutions of cysteines (C848, C853, C870) in the GluN2A subunit, alone or in combination with phenylalanine substitution of tyrosine (Y842), indicating that cysteine modification could be a contributing factor in the control of the potentiating effect of docosahexaenoic acid at the NMDAR (Wilding et al., 2016).
The increase in the $\left[\mathrm{Ca}^{2+}\right]_{\mathrm{i}}$ following NMDAR activation is necessary for normal synaptic transmission and triggers cellular processes associated with LTP and LTD. However, pathologic overactivation of NMDARs and the resulting prolonged $\left[\mathrm{Ca}^{2+}\right]_{\mathrm{i}}$ elevation is harmful for neurons. Therefore, $\left[\mathrm{Ca}^{2+}\right]_{\mathrm{i}}$ is tightly regulated by cellular buffers and pumps and also by direct $\mathrm{Ca}^{2+}$. mediated negative feedback that controls NMDAR activity (Mayer and Westbrook, 1985; Zorumski et al., 1989; Legendre et al., 1993; Vyklicky, 1993; Medina et al., 1995; Iacobucci and Popescu, 2020). Our results suggest that the GluN2B subunit CTD depalmitoylation may provide an additional mechanism for the control of $\mathrm{Ca}^{2+}$ entry at synaptic and extrasynaptic sites.

In conclusion, based on the results reported here, we propose a mechanism whereby palmitoylation of the GluN2B subunit regulates the NMDAR sensitivity to inhibitory neurosteroids and influences receptor gating. In addition, we explore molecular mechanisms of palmitoylation-dependent structural changes at the GluN2B subunit CTD and TMD. Deeper understanding of this novel regulation of neurosteroid inhibition could be used for the development of new therapeutic strategies in the treatment of neurologic and psychiatric disorders associated with pathologic NMDAR function.

\section{References}

Abraham MJ, Murtola T, Schulz R, Pall S, Smith JC, Hess B, Lindahl E (2015) GROMACS: high performance molecular simulations through multilevel parallelism from laptops to supercomputers. SoftwareX 1:19-25.

Adla SK, Slavikova B, Smidkova M, Tloustova E, Svoboda M, Vyklicky V, Krausova B, Hubalkova P, Nekardova M, Holubova K, Vales K, Budesinsky M, Vyklicky L, Chodounska H, Kudova E (2017) Physicochemical and biological properties of novel amide-based steroidal inhibitors of NMDA receptors. Steroids 117:52-61.

Amico-Ruvio SA, Popescu GK (2010) Stationary gating of GluN1/GluN2B receptors in intact membrane patches. Biophys J 98:1160-1169.

Banke TG, Traynelis SF (2003) Activation of NR1/NR2B NMDA receptors. Nat Neurosci 6:144-152.

Borovska J, Vyklicky V, Stastna E, Kapras V, Slavikova B, Horak M, Chodounska H, Vyklicky L Jr (2012) Access of inhibitory neurosteroids to the NMDA receptor. Br J Pharmacol 166:1069-1083.

Bouvier G, Larsen RS, Rodríguez-Moreno A, Paulsen O, Sjöström PJ (2018) Towards resolving the presynaptic NMDA receptor debate. Curr Opin Neurobiol 51:1-7.

Cerny J, Bozõíková P, Balík A, Marques SM, Vyklický L (2019) NMDA receptor opening and closing: transitions of a molecular machine revealed by molecular dynamics. Biomolecules 9:546.

Charollais J, Van Der Goot FG (2009) Palmitoylation of membrane proteins (Review). Mol Membr Biol 26:55-66.

Choi DW (1987) Ionic dependence of glutamate neurotoxicity. J Neurosci 7:369-379.

Choi DW, Koh JY, Peters S (1988) Pharmacology of glutamate neurotoxicity in cortical cell culture: attenuation by NMDA antagonists. J Neurosci 8:185-196.

Colquhoun D, Hawkes AG (1990) Stochastic properties of ion channel openings and bursts in a membrane patch that contains two channels: evidence concerning the number of channels present when a record containing only single openings is observed. Proc R Soc Lond B Biol Sci 240:453-477.

Conibear E, Davis NG (2010) Palmitoylation and depalmitoylation dynamics at a glance. J Cell Sci 123:4007-4010.

Constantine-Paton M, Cline HT, Debski E (1990) Patterned activity, synaptic convergence, and the NMDA receptor in developing visual pathways. Annu Rev Neurosci 13:129-154.

Ehlers MD, Zhang S, Bernhadt JP, Huganir RL (1996) Inactivation of NMDA receptors by direct interaction of calmodulin with the NR1 subunit. Cell 84:745-755.

Gibb AJ, Colquhoun D (1991) Glutamate activation of a single NMDA receptor-channel produces a cluster of channel openings. Proc R Soc Lond B Biol Sci 243:39-45. 
Gonnord P, Delarasse C, Auger R, Benihoud K, Prigent M, Cuif MH, Lamaze C, Kanellopoulos JM (2009) Palmitoylation of the P2X7 receptor, an ATP-gated channel, controls its expression and association with lipid rafts. FASEB J 23:795-805.

Gubitosi-Klug RA, Mancuso DJ, Gross RW (2005) The human Kv1.1 channel is palmitoylated, modulating voltage sensing: identification of a palmitoylation consensus sequence. Proc Natl Acad Sci USA 102:59645968.

Hansen KB, Yi F, Perszyk RE, Furukawa H, Wollmuth LP, Gibb AJ, Traynelis SF (2018) Structure, function, and allosteric modulation of NMDA receptors. J Gen Physiol 150:1081-1105.

Hardingham G (2019) NMDA receptor C-terminal signaling in development, plasticity, and disease. F1000Res 8:1547.

Hardingham GE, Bading H (2010) Synaptic versus extrasynaptic NMDA receptor signalling: implications for neurodegenerative disorders. Nat Rev Neurosci 11:682-696.

Hayashi T (2020) Post-translational palmitoylation of ionotropic glutamate receptors in excitatory synaptic functions. Br J Pharmacol. Advance online publication. Retrieved Mar 11, 2020. doi: 10.1111/bph.15050.

Hayashi T, Rumbaugh G, Huganir RL (2005) Differential regulation of AMPA receptor subunit trafficking by palmitoylation of two distinct sites. Neuron 47:709-723.

Hayashi T, Thomas GM, Huganir RL (2009) Dual palmitoylation of NR2 subunits regulates NMDA receptor trafficking. Neuron 64:213-226.

Hrcka Krausova B, Kysilov B, Cerny J, Vyklicky V, Smejkalova T, Ladislav M, Balik A, Korinek M, Chodounska H, Kudova E, Vyklicky L (2020) Site of action of brain neurosteroid pregnenolone sulfate at the Nmethyl-D-aspartate receptor. J Neurosci 40:5922-5936.

Iacobucci GJ, Popescu GK (2020) $\mathrm{Ca}(2+)$-dependent inactivation of GluN2A and GluN2B NMDA receptors occurs by a common kinetic mechanism. Biophys J 118:798-812.

Jo S, Kim T, Iyer VG, Im W (2008) CHARMM-GUI: a web-based graphical user interface for CHARMM. J Comput Chem 29:1859-1865.

Jurd R, Thornton C, Wang J, Luong K, Phamluong K, Kharazia V, Gibb SL, Ron D (2008) Mind bomb-2 is an E3 ligase that ubiquitinates the Nmethyl-D-aspartate receptor NR2B subunit in a phosphorylation-dependent manner. J Biol Chem 283:301-310.

Karakas E, Furukawa H (2014) Crystal structure of a heterotetrameric NMDA receptor ion channel. Science 344:992-997.

Kazi R, Dai J, Sweeney C, Zhou HX, Wollmuth LP (2014) Mechanical coupling maintains the fidelity of NMDA receptor-mediated currents. Nat Neurosci 17:914-922.

Klauda JB, Venable RM, Freites JA, O'Connor JW, Tobias DJ, MondragonRamirez C, Vorobyov I, MacKerell AD Jr, Pastor RW (2010) Update of the CHARMM all-atom additive force field for lipids: validation on six lipid types. J Phys Chem B 114:7830-7843.

Kornau HC, Schenker LT, Kennedy MB, Seeburg PH (1995) Domain interaction between NMDA receptor subunits and the postsynaptic density protein PSD-95. Science 269:1737-1740.

Krupp JJ, Vissel B, Thomas CG, Heinemann SF, Westbrook GL (1999) Interactions of calmodulin and alpha-actinin with the NR1 subunit modulate $\mathrm{Ca}^{2+}$-dependent inactivation of NMDA receptors. J Neurosci 19:1165-1178.

Kutsuwada T, Kashiwabuchi N, Mori H, Sakimura K, Kushiya E, Araki K, Meguro H, Masaki H, Kumanishi T, Arakawa M (1992) Molecular diversity of the NMDA receptor channel. Nature 358:36-41.

Ladislav M, Cerny J, Krusek J, Horak M, Balik A, Vyklicky L (2018) The LILI motif of M3-S2 linkers is a component of the NMDA receptor channel gate. Front Mol Neurosci 11:113.

Lan JY, Skeberdis VA, Jover T, Grooms SY, Lin Y, Araneda RC, Zheng X, Bennett MV, Zukin RS (2001) Protein kinase C modulates NMDA receptor trafficking and gating. Nat Neurosci 4:382-390.

Lee CH, Lu W, Michel JC, Goehring A, Du J, Song X, Gouaux E (2014) NMDA receptor structures reveal subunit arrangement and pore architecture. Nature 511:191-197.

Lee J, Cheng X, Swails JM, Yeom MS, Eastman PK, Lemkul JA, Wei S, Buckner J, Jeong JC, Qi Y, Jo S, Pande VS, Case DA, Brooks CL 3rd, MacKerell AD Jr, Klauda JB, Im W (2016) CHARMM-GUI input generator for NAMD, GROMACS, AMBER, OpenMM, and CHARMM/ OpenMM simulations using the CHARMM36 additive force field. J Chem Theory Comput 12:405-413.
Legendre P, Rosenmund C, Westbrook GL (1993) Inactivation of NMDA channels in cultured hippocampal neurons by intracellular calcium. J Neurosci 13:674-684

Lin DT, Makino Y, Sharma K, Hayashi T, Neve R, Takamiya K, Huganir RL (2009) Regulation of AMPA receptor extrasynaptic insertion by $4.1 \mathrm{~N}$, phosphorylation and palmitoylation. Nat Neurosci 12:879-887.

Lussier MP, Sanz-Clemente A, Roche KW (2015) Dynamic regulation of Nmethyl-D-aspartate (NMDA) and alpha-amino-3-hydroxy-5-methyl-4isoxazolepropionic acid (AMPA) receptors by posttranslational modifications. J Biol Chem 290:28596-28603.

Lynch MA (2004) Long-term potentiation and memory. Physiol Rev 84:87136.

MacDermott AB, Mayer ML, Westbrook GL, Smith SJ, Barker JL (1986) NMDA-receptor activation increases cytoplasmic calcium concentration in cultured spinal cord neurones. Nature 321:519-522.

Maki BA, Aman TK, Amico-Ruvio SA, Kussius CL, Popescu GK (2012) Cterminal domains of $\mathrm{N}$-methyl-D-aspartic acid receptor modulate unitary channel conductance and gating. J Biol Chem 287:36071-36080.

Malenka RC, Bear MF (2004) LTP and LTD: an embarrassment of riches. Neuron 44:5-21.

Mayer ML, Westbrook GL (1985) The action of N-methyl-D-aspartic acid on mouse spinal neurones in culture. J Physiol 361:65-90.

Mayer ML, MacDermott AB, Westbrook GL, Smith SJ, Barker JL (1987) Agonist- and voltage-gated calcium entry in cultured mouse spinal cord neurons under voltage clamp measured using arsenazo III. J Neurosci $7: 3230-3244$.

Medina I, Filippova N, Charton G, Rougeole S, Ben-Ari Y, Khrestchatisky M, Bregestovski P (1995) Calcium-dependent inactivation of heteromeric NMDA receptor-channels expressed in human embryonic kidney cells. J Physiol 482:567-573.

Meguro H, Mori H, Araki K, Kushiya E, Kutsuwada T, Yamazaki M, Kumanishi T, Arakawa M, Sakimura K, Mishina M (1992) Functional characterization of a heteromeric NMDA receptor channel expressed from cloned cDNAs. Nature 357:70-74

Monyer H, Sprengel R, Schoepfer R, Herb A, Higuchi M, Lomeli H, Burnashev N, Sakmann B, Seeburg PH (1992) Heteromeric NMDA receptors: molecular and functional distinction of subtypes. Science 256:1217-1221.

Moriyoshi K, Masu M, Ishii T, Shigemoto R, Mizuno N, Nakanishi S (1991) Molecular cloning and characterization of the rat NMDA receptor. Nature 354:31-37.

Murphy JA, Stein IS, Lau CG, Peixoto RT, Aman TK, Kaneko N, Aromolaran K, Saulnier JL, Popescu GK, Sabatini BL, Hell JW, Zukin RS (2014) Phosphorylation of Ser1166 on GluN2B by PKA is critical to synaptic NMDA receptor function and $\mathrm{Ca}^{2+}$ signaling in spines. J Neurosci 34:869-879.

Park-Chung M, Wu FS, Farb DH (1994) 3 alpha-Hydroxy- 5 beta-pregnan20-one sulfate: a negative modulator of the NMDA-induced current in cultured neurons. Mol Pharmacol 46:146-150.

Patterson SI, Skene JH (1995) Inhibition of dynamic protein palmitoylation in intact cells with tunicamycin. Methods Enzymol 250:284-300.

Petrovic M, Sedlacek M, Horak M, Chodounska H, Vyklicky L Jr (2005) 20oxo-5beta-pregnan-3alpha-yl sulfate is a use-dependent NMDA receptor inhibitor. J Neurosci 25:8439-8450.

Pickering DS, Taverna FA, Salter MW, Hampson DR (1995) Palmitoylation of the GluR6 kainate receptor. Proc Natl Acad Sci USA 92:12090-12094.

Popescu G, Auerbach A (2003) Modal gating of NMDA receptors and the shape of their synaptic response. Nat Neurosci 6:476-483.

Popescu G, Robert A, Howe JR, Auerbach A (2004) Reaction mechanism determines NMDA receptor response to repetitive stimulation. Nature 430:790-793.

Punnakkal P, Jendritza P, Kohr G (2012) Influence of the intracellular GluN2 C-terminal domain on NMDA receptor function. Neuropharmacology 62:1985-1992.

Qin F (2004) Restoration of single-channel currents using the segmental $k$ means method based on hidden Markov modeling. Biophys J 86:14881501.

Qin F, Auerbach A, Sachs F (1997) Maximum likelihood estimation of aggregated Markov processes. Proc Biol Sci 264:375-383.

Qin N, Platano D, Olcese R, Costantin JL, Stefani E, Birnbaumer L (1998) Unique regulatory properties of the type $2 \mathrm{a} \mathrm{Ca}^{2+}$ channel beta subunit caused by palmitoylation. Proc Natl Acad Sci USA 95:4690-4695. 
Rathenberg J, Kittler JT, Moss SJ (2004) Palmitoylation regulates the clustering and cell surface stability of GABAA receptors. Mol Cell Neurosci 26:251-257.

Rosenmund C, Westbrook GL (1993) Calcium-induced actin depolymerization reduces NMDA channel activity. Neuron 10:805-814.

Ryan TJ, Emes RD, Grant SG, Komiyama NH (2008) Evolution of NMDA receptor cytoplasmic interaction domains: implications for organisation of synaptic signalling complexes. BMC Neurosci 9:6.

Sali A, Blundell TL (1993) Comparative protein modelling by satisfaction of spatial restraints. J Mol Biol 234:779-815.

Shipston MJ (2011) Ion channel regulation by protein palmitoylation. J Biol Chem 286:8709-8716.

Skeberdis VA, Chevaleyre V, Lau CG, Goldberg JH, Pettit DL, Suadicani SO, Lin Y, Bennett MV, Yuste R, Castillo PE, Zukin RS (2006) Protein kinase A regulates calcium permeability of NMDA receptors. Nat Neurosci 9:501-510

Stastna E, Chodounska H, Pouzar V, Kapras V, Borovska J, Cais O, Vyklicky L Jr (2009) Synthesis of C3, C5, and C7 pregnane derivatives and their effect on NMDA receptor responses in cultured rat hippocampal neurons. Steroids 74:256-263.

Stern MD (1992) Buffering of calcium in the vicinity of a channel pore. Cell Calcium 13:183-192.

Sucher NJ, Akbarian S, Chi CL, Leclerc CL, Awobuluyi M, Deitcher DL, Wu MK, Yuan JP, Jones EG, Lipton SA (1995) Developmental and regional expression pattern of a novel NMDA receptor-like subunit (NMDAR-L) in the rodent brain. J Neurosci 15:6509-6520.

Tong G, Shepherd D, Jahr CE (1995) Synaptic desensitization of NMDA receptors by calcineurin. Science 267:1510-1512.

Traynelis SF, Wollmuth LP, McBain CJ, Menniti FS, Vance KM, Ogden KK, Hansen KB, Yuan H, Myers SJ, Dingledine R, Sibley D (2010) Glutamate receptor ion channels: structure, regulation, and function. Pharmacol Rev 62:405-496.

UniProt C (2019) UniProt: a worldwide hub of protein knowledge. Nucleic Acids Res 47:D506-D515.
Vieira M, Yong XL, Roche KW, Anggono V (2020) Regulation of NMDA glutamate receptor functions by the GluN2 subunits. J Neurochem 154:121-143.

Vyklicky L Jr (1993) Calcium-mediated modulation of N-methyl-D-aspartate (NMDA) responses in cultured rat hippocampal neurones. J Physiol Lond 470:575-600.

Vyklicky V, Krausova B, Cerny J, Balik A, Zapotocky M, Novotny M, Lichnerova K, Smejkalova T, Kaniakova M, Korinek M, Petrovic M, Kacer P, Horak M, Chodounska H, Vyklicky L (2015) Block of NMDA receptor channels by endogenous neurosteroids: implications for the agonist induced conformational states of the channel vestibule. Sci Rep 5:10935.

Vyklicky V, Smejkalova T, Krausova B, Balik A, Korinek M, Borovska J, Horak M, Chvojkova M, Kleteckova L, Vales K, Cerny J, Nekardova M, Chodounska H, Kudova E, Vyklicky L (2016) Preferential inhibition of tonically over phasically activated NMDA receptors by pregnane derivatives. J Neurosci 36:2161-2175.

Warnet XL, Bakke Krog H, Sevillano-Quispe OG, Poulsen H, Kjaergaard M (2020) The C-terminal domains of the NMDA receptor: how intrinsically disordered tails affect signalling, plasticity and disease. Eur J Neurosci. Advance online publication. Retrieved May 28, 2020. doi: 10.1111/ ejn. 14842 .

Webb B, Sali A (2014) Comparative protein structure modeling using MODELLER. Curr Protoc Bioinformatics 47:1-32.

Wilding TJ, Lopez MN, Huettner JE (2016) Chimeric glutamate receptor subunits reveal the transmembrane domain is sufficient for NMDA receptor pore properties but some positive allosteric modulators require additional domains. J Neurosci 36:8815-8825.

Wyszynski M, Lin J, Rao A, Nigh E, Beggs AH, Craig AM, Sheng M (1997) Competitive binding of alpha-actinin and calmodulin to the NMDA receptor. Nature 385:439-442.

Zorumski CF, Yang J, Fischbach GD (1989) Calcium-dependent, slow desensitization distinguishes different types of glutamate receptors. Cell Mol Neurobiol 9:95-104. 